Article

\title{
Estimation of the Biot Number Using Genetic Algorithms: Application for the Drying Process
}

\author{
Krzysztof Górnicki * (1), Radosław Winiczenko and Agnieszka Kaleta \\ Department of Fundamental Engineering, Warsaw University of Life Sciences, Nowoursynowska 164 St., \\ 02-787 Warsaw, Poland \\ * Correspondence: krzysztof_gornicki@sggw.pl; Tel.: +48-22-593-46-18
}

Received: 28 May 2019; Accepted: 17 July 2019; Published: 22 July 2019

check for updates

\begin{abstract}
The Biot number informs researchers about the controlling mechanisms employed for heat or mass transfer during the considered process. The mass transfer coefficients (and heat transfer coefficients) are usually determined experimentally based on direct measurements of mass (heat) fluxes or correlation equations. This paper presents the method of Biot number estimation. For estimation of the Biot number in the drying process, the multi-objective genetic algorithm (MOGA) was developed. The simultaneous minimization of mean absolute error (MAE) and root mean square error (RMSE) and the maximization of the coefficient of determination $R^{2}$ between the drying model and experimental data were considered. The Biot number can be calculated from the following equations: $B i=0.8193 \exp \left(-6.4951 T^{-1}\right)$ (and moisture diffusion coefficient from $D / s^{2}=0.00704 \exp \left(-2.54 T^{-1}\right)$ ) $\left(\mathrm{RMSE}=0.0672, \mathrm{MAE}=0.0535, R^{2}=0.98\right)$ or $B i=1 / 0.1746 \log (1193847 \mathrm{~T})\left(D / \mathrm{s}^{2}=0.0075 \exp \left(-6 T^{-1}\right)\right)$ (RMSE $\left.=0.0757, \mathrm{MAE}=0.0604, R^{2}=0.98\right)$. The conducted validation gave good results.
\end{abstract}

Keywords: Biot number; genetic algorithms; drying

\section{Introduction}

The dimensionless Biot number $(B i)$ is present in partial differential equations in cases when the surface boundary conditions (of the third kind) are written in a dimensionless form. The Biot number informs researchers about the relationship between the internal and external fluxes [1]. As far as heat transfer is concerned, Bi expresses the ratio between the internal and external resistances [2]. Therefore, it can be stated that the heat Biot number is a measure of the temperature drop in the material with respect to the difference of the temperatures between the solid surface and the surrounding medium [3]. Assuming similarity between heat and mass transfer, the Biot number used for mass exchange is gained by equating internal and external mass fluxes at the interface $[3,4]$ and the discussed number is defined as follows:

$$
B i=\frac{h_{m} L}{D},
$$

The analysis of Biot numbers enables researchers to answer questions regarding the controlling mechanisms employed for heat or mass transfer during the considered process [3]. Dincer [3] stated that the values of $B i$ for mass transfer can be divided into the following groups:

$B i<0.1$ (the surface resistance across the surrounding medium boundary layer is much bigger in comparison with the internal resistance to the mass diffusion within the solid body);

$0.1<B i<100$ (the values of the internal and external resistance can be treated as comparable);

$B i>100$ (external (surface) resistance is much lower than the internal resistance).

Ruiz-López et al. $[5,6]$ assumed that for $B i>40$, it can be accepted that the internal resistance to mass exchange is the only mechanism controlling the rate of the drying process. In such a case, the moisture content of the solid body surface reaches its equilibrium value at once. Wu and 
Irudayaraj [7] experimentally stated that drying can only be treated as an isothermal process for very low Biot numbers.

The mass transfer coefficients (and heat transfer coefficients) are usually determined experimentally based on direct measurements of mass (heat) fluxes or correlation equations. The mass transfer coefficient can also be calculated from the dimensionless Sherwood number $(S h)$. The $S h$ can be expressed as a function of the Reynolds number $(R e)$ and the Schmidt number ( $S c$ ) (forced convection), as a function of the Grashof number (mass) $\left(G r_{m}\right)$ and the $S c$ (natural convection), and as a function of the Archimedes number $(A r)$ and the $S c$ (vacuum-microwave drying) [8].

The importance of the heat and mass Biot number has been shown in several publications. Rovedo et al. [4] analysed the drying process of shrinking potato slabs. The numerical solving of the drying model using various forms of Bi gave a deeper insight into the process. Huang and Yeh [9] considered an inverse problem in simultaneously estimating the heat and mass Biot numbers during the drying of a porous material. Dincer and Hussain [10] developed a new Biot number and lag factor correlation, which gave good agreement between the predicted and measured values of moisture content. Chen and Peng [11] analysed the values of modified Biot numbers during hot air drying of small, moist, and porous objects. Giner et al. [1] considered the variableness of heat and mass Bi during the drying of wheat and apple-leather, whereas Xie et al. [12] modelled the pulsed vacuum drying of rhizoma dioscoreae slices using the Dincer model [13], which describes the moisture ratio with a correlation between $B i$ and the lag factor.

An accurate estimation of the Biot number is essential for an efficient heat and mass transfer analysis, leading to optimum operating conditions and an efficient process.

The aim of the multi-objective optimization task is to optimize the several objective functions simultaneously with many criteria. These issues have long been of interest to researchers using traditional optimization and search techniques. In the case of multi-criteria optimization, the concept of the optimal solution is not as obvious as in the case of one criterion. If we do not agree in advance to compare the values of different criteria, then we must propose a definition of optimality that respects the integrity of each of them. This approach is called optimality in the Pareto sense. It is convenient to classify possible solutions of multi-criteria optimization tasks as dominated and non-dominated (Pareto-optimal) solutions.

Multi-criteria optimization of drying technology is used for conveyer-belt dryer design [14,15], fluidized bed dryers [16,17], control of a drying process [18], batch drying of rice [19], and drying [20] and rehydrated apple issue [21]. Non-preference multi-criterion optimization methods with the Pareto-optimal set were used in the papers [14-17]. The researchers developed a mathematical model of the fluidized bed dryer and determined the colour deterioration laws for potato slices. A multi-criterion optimization of the thermal processing was conducted by [22] and [23]. The authors developed an intelligent hybrid method for identifying the optimal processing conditions. The complex method applied to different shapes was subjected to the processing boundary conditions to find the best process temperature and to maximize the retention of thiamine. Winiczenko et al. predicted the quality indicators of the drying [20] and rehydrated [21] apple issue using a non-sorting genetic algorithm.

The aim of the present study is to determine the Biot number using the genetics algorithm (GA). The method is applied in the process of drying.

\section{Materials and Methods}

\subsection{Material}

The research material was parsley roots of the Berlińska variety. The parsley roots were purchased at a local market in Warsaw. The material was cut into $6 \mathrm{~mm}$ thick slices, which were dried in natural convection conditions at the temperatures of $40,50,60$, and $70^{\circ} \mathrm{C}$.

A detailed description of the equipment used, measurements performed, and their accuracy may be found in [24]. 


\subsection{Moisture Transfer Analysis}

It can be assumed that the moisture movement inside the dried solid body is only a diffusion movement in the convection drying of food products. The unsteady-state, one-dimensional mass exchange equation within a slice (treated as an infinite plane) of a thickness of $2 s$ can be expressed in the following form [25]:

$$
\frac{\partial M}{\partial t}=D \frac{\partial^{2} M}{\partial x^{2}}(t>0 ;-s<x<s) .
$$

The following common assumptions were taken in Equation (2):

- Shape and volume of the slice do not change during drying;

- Mass diffusion coefficient is constant;

- Equation (2) is subjected to the following conditions:

Moisture content at any point of the slice is the same at the beginning of drying (initial condition):

$$
M(x, 0)=M_{0}=\text { const, }
$$

The mass flux from the surface of the slice is expressed in terms of the moisture content difference between the surface and the equilibrium moisture content (boundary conditions of the third kind):

$$
\pm D \frac{\partial M( \pm s, t)}{\partial x}=k\left[M( \pm s, t)-M_{e}\right]
$$

An analytical solution of Equation (2) at the initial condition in the form of Equation (3) and at the boundary conditions given by Equation (4) with respect to the mean moisture content as function of time can be written in the following form [25]:

$$
M R=\frac{M-M_{e}}{M_{0}-M_{e}}=\sum_{i=1}^{\infty} B_{i} \exp \left[-\mu_{i}^{2} \frac{D}{s^{2}} t\right],
$$

where

$$
\begin{gathered}
B_{i}=\frac{2 B i^{2}}{\mu_{i}{ }^{2} B i^{2}+B i+\mu_{i}{ }^{2}}, \\
\operatorname{ctg} \mu_{i}=\frac{1}{B i} \mu_{i},
\end{gathered}
$$

The Biot number in Equations (6) and (7) was assumed to be dependent on the temperature using the following formulas:

$$
\begin{gathered}
B i=a_{b} \exp \left(-\frac{b_{b}}{T}\right), \\
B i=a_{b} \ln \left(b_{b} T\right), \\
B i=a_{b} \log \left(b_{b} T\right), \\
B i=a_{b} \ln (T)+b_{b}, \\
B i=a_{b} T^{-b_{b},} \\
B i=\frac{1}{a_{b} \ln \left(b_{b} T\right)^{\prime}}, \\
B i=\frac{1}{a_{b} \log \left(b_{b} T\right)}, \\
B i=\frac{1}{a_{b} \exp \left(-\frac{b_{b}}{T}\right)},
\end{gathered}
$$


Dependencies (8a)-(8d) indicate the increase of the Biot number with the increase of the temperature, whereas dependencies $(8 \mathrm{e})-(8 \mathrm{~h})$ indicate the decrease of $B i$ with the increase of the temperature (i.e., [26]).

The moisture diffusion coefficient in Equation (5) was assumed to be dependent on the temperature using the following formula (i.e., $[27,28])$ :

$$
\frac{D}{s^{2}}=a_{d} \exp \left(-\frac{b_{d}}{T}\right)
$$

An increase of the temperature according to Equation (9) results in a increase of the moisture diffusion coefficient.

\subsection{Optimization}

The optimization problem has been divided into two tasks. The first multi-objective optimization (MOO) task was to determine a Biot number and mass diffusion coefficient from the moisture ratio (MR) model (5) for each drying temperature: $40,50,60$, and $70^{\circ} \mathrm{C}$. The second optimization task was to find the constants in equations for calculation of the Biot number (8a)-(8h) and mass diffusion coefficient (9).

The mean absolute error (MAE) and root mean square error (RMSE) were minimized, whereas the coefficient of determination $\mathrm{R}^{2}$ was maximized for the difference between the data and objective function for both optimized tasks. The algorithm randomly selects a set of models by minimizing the error between the proposed model and experimental data. Then, it evolves them to create the best fit. Therefore, the MOO problem was expressed as follows:

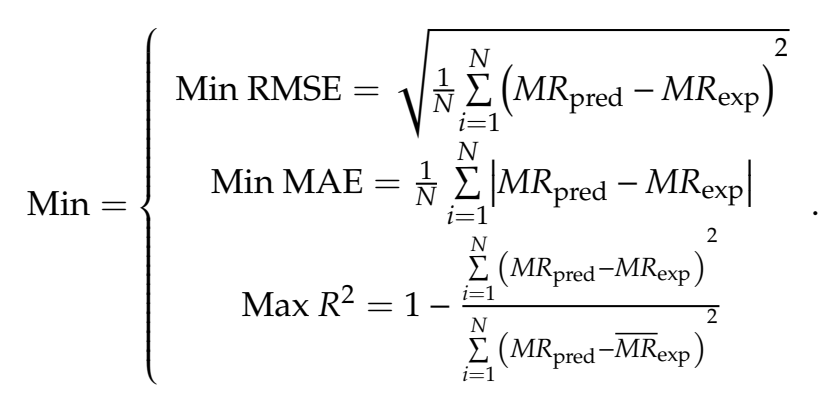

The multi-objective optimization was carried out using an elitist, non-dominated sorting genetic algorithm (NSGA II). The Pareto front for this problem was created using Optimization Toolbox ${ }^{\mathrm{TM}}$ realized in MATLAB R2018. The multi-objective genetic algorithm (MOGA) options are shown in Table 1.

Table 1. The multi-objective genetic algorithm (MOGA) settings.

\begin{tabular}{cc}
\hline Parameter & Value \\
\hline Crossover coefficient & 0.8 \\
Crossover function & Intermediate \\
Mutation coefficient & 0.2 \\
Mutation function & Uniform \\
Number generations & $500 \cdot$ number of variables \\
Population size & 60·number of variables \\
Selection function & Turnament size $=2$ \\
\hline
\end{tabular}




\section{Results}

\subsection{Case 1. Optimizaton of the Biot Number}

The results of optimization described by Equation (10) are presented in Table 2 and Figures 1 and 2. The Pareto set of the Biot number for the $T$ of $40{ }^{\circ} \mathrm{C}$ indicates that in the case of searching for the smallest values of RMSE, the best solution is ID 40_1 (0.04441). For ID 40_2, the value of $R^{2}$ is the greatest (0.9937). The solution of MAE minimization is ID 40_5 (0.03652). The set of the best solutions for $40{ }^{\circ} \mathrm{C}$ (marked in Figure 1) indicates the greatest dispersion of solutions compared with the best solutions for other drying temperatures examined. The Biot number determined for the drying temperature of $50{ }^{\circ} \mathrm{C}$ has the smallest RMSE for ID 50_1 (0.03731). The value of $R^{2}$ is the greatest for ID 50_2 (0.9955). The solution of MAE minimization is ID 50_3 (0.03228). The dispersion of the best solutions is smaller than for the temperature of $40{ }^{\circ} \mathrm{C}$ (Figure 1), and the solutions are characterised by the best statistics. The Biot number determined for the drying temperature of $60^{\circ} \mathrm{C}$ has the smallest RMSE for ID 60_1 and 60_2 (0.04072-0.04073, difference 0.00001). For ID 60_4, the value of $R^{2}$ is the greatest (0.9948). The solution of MAE minimization is ID 60_4 i 60_3 (0.03640 and 0.03641 , difference 0.00001 ). The set of best solutions for $60^{\circ} \mathrm{C}$ (Figure 1 ) is characterised by small (the smallest) dispersion. The Biot number determined for the drying temperature of $70^{\circ} \mathrm{C}$ has the smallest RMSE and the greatest $R^{2}$ for ID 70_1-70_3 (0.03888-0.03889 and 0.9943, respectively). The solution of MAE minimization is ID 70_4 (0.03420), with the solutions for ID 70_5, 70_2, 70_3, and $70 \_1$ being slightly worse $(0.03424,0.03427,0.03428$, and 0.03429 , difference 0.00009$)$. The set of best solutions for $70{ }^{\circ} \mathrm{C}$ (Figure 1) is only characterised by a very small amount of dispersion when the MAE minimization criterion is not considered.

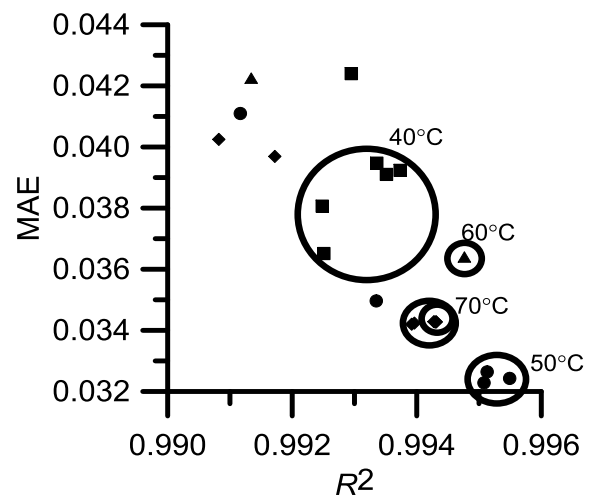

(a)

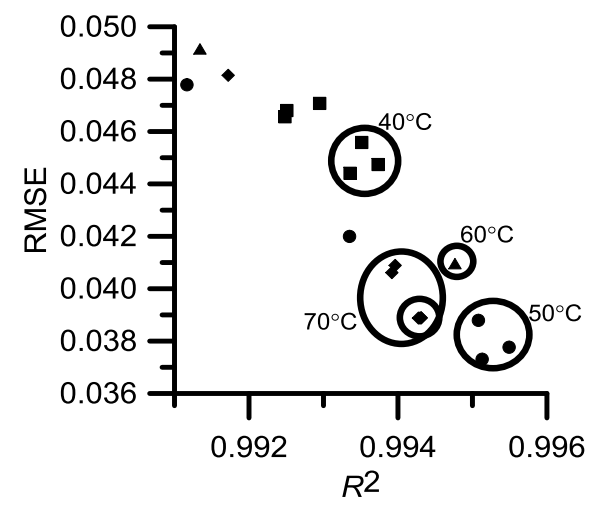

(b)

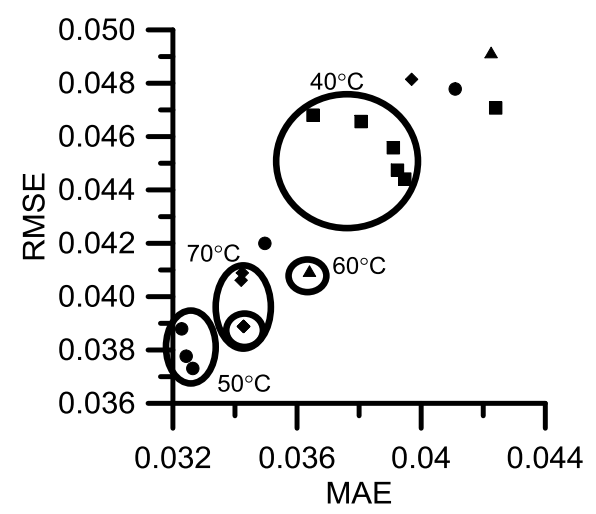

(c)

Figure 1. Results of the statistical analysis of Pareto optimal sets for the Biot number: $(\boldsymbol{\square}) \mathrm{T}=40^{\circ} \mathrm{C}$, (•) $\mathrm{T}=50^{\circ} \mathrm{C},(\boldsymbol{\Delta}) \mathrm{T}=60^{\circ} \mathrm{C}$, and $(\bullet) \mathrm{T}=70^{\circ} \mathrm{C}$. 
Table 2. Pareto optimal set for the Biot number $(B i)$ and $D / s^{2}$ and results of the statistical analysis.

\begin{tabular}{|c|c|c|c|c|c|c|}
\hline Temperature, ${ }^{\circ} \mathrm{C}$ & ID & $B i$ & $D / s^{2}\left(\min ^{-1}\right)$ & $R^{2}$ & RMSE & MAE \\
\hline \multirow{10}{*}{40} & 40_1 & 0.7233 & 0.00610 & 0.9934 & 0.04441 & 0.03947 \\
\hline & 40_2 & 0.7243 & 0.00601 & 0.9937 & 0.04474 & 0.03924 \\
\hline & 40_3 & 0.7016 & 0.00625 & 0.9935 & 0.04558 & 0.03910 \\
\hline & $40 \_4$ & 0.7548 & 0.00442 & 0.9925 & 0.04656 & 0.03807 \\
\hline & $40 \_5$ & 0.7450 & 0.00454 & 0.9925 & 0.04680 & 0.03652 \\
\hline & $40 \_6$ & 0.7555 & 0.00601 & 0.9930 & 0.04707 & 0.04240 \\
\hline & 40_7 & 0.7749 & 0.00532 & 0.9858 & 0.07744 & 0.06666 \\
\hline & 40_8 & 0.6745 & 0.00883 & 0.9820 & 0.07770 & 0.06498 \\
\hline & 40_9 & 0.6901 & 0.00883 & 0.9804 & 0.08622 & 0.07129 \\
\hline & 40_10 & 0.6555 & 0.00990 & 0.9748 & 0.10327 & 0.08541 \\
\hline \multirow{10}{*}{50} & 50_1 & 0.7245 & 0.00615 & 0.9951 & 0.03731 & 0.03264 \\
\hline & 50_2 & 0.7231 & 0.00605 & 0.9955 & 0.03777 & 0.03243 \\
\hline & 50_3 & 0.7012 & 0.00635 & 0.9951 & 0.03879 & 0.03228 \\
\hline & 50_4 & 0.6967 & 0.00698 & 0.9934 & 0.04200 & 0.03496 \\
\hline & 50_5 & 0.6967 & 0.00747 & 0.9912 & 0.04779 & 0.04110 \\
\hline & $50 \_6$ & 0.7283 & 0.00734 & 0.9897 & 0.06001 & 0.05115 \\
\hline & 50_7 & 0.6506 & 0.00884 & 0.9867 & 0.06764 & 0.05661 \\
\hline & $50 \_8$ & 0.7040 & 0.00824 & 0.9858 & 0.07501 & 0.06318 \\
\hline & 50_9 & 0.6540 & 0.00912 & 0.9836 & 0.07945 & 0.06742 \\
\hline & 50_10 & 0.7040 & 0.00873 & 0.9828 & 0.08853 & 0.07409 \\
\hline \multirow{10}{*}{60} & 60_1 & 0.7017 & 0.00788 & 0.9944 & 0.04072 & 0.03646 \\
\hline & 60_2 & 0.7017 & 0.00791 & 0.9943 & 0.04073 & 0.03654 \\
\hline & 60_3 & 0.7086 & 0.00780 & 0.9946 & 0.04085 & 0.03641 \\
\hline & 60_4 & 0.7001 & 0.00775 & 0.9948 & 0.04096 & 0.03640 \\
\hline & 60_5 & 0.7095 & 0.00872 & 0.9913 & 0.04916 & 0.04225 \\
\hline & 60_6 & 0.7337 & 0.00838 & 0.9917 & 0.05097 & 0.04363 \\
\hline & 60_7 & 0.6507 & 0.01012 & 0.9889 & 0.05853 & 0.04684 \\
\hline & $60 \_8$ & 0.6513 & 0.01016 & 0.9888 & 0.05896 & 0.04720 \\
\hline & 60_9 & 0.7152 & 0.00958 & 0.9875 & 0.06637 & 0.05393 \\
\hline & 60_10 & 0.6791 & 0.01046 & 0.9845 & 0.07567 & 0.06103 \\
\hline \multirow{10}{*}{70} & 70_1 & 0.7003 & 0.01012 & 0.9943 & 0.03888 & 0.03429 \\
\hline & 70_2 & 0.7005 & 0.01011 & 0.9943 & 0.03888 & 0.03427 \\
\hline & 70_3 & 0.7014 & 0.01011 & 0.9943 & 0.03889 & 0.03428 \\
\hline & 70_4 & 0.6789 & 0.01062 & 0.9939 & 0.04061 & 0.03420 \\
\hline & 70_5 & 0.6898 & 0.01060 & 0.9940 & 0.04089 & 0.03424 \\
\hline & 70_6 & 0.7043 & 0.01120 & 0.9917 & 0.04815 & 0.03969 \\
\hline & 70_7 & 0.6525 & 0.01260 & 0.9908 & 0.05378 & 0.04025 \\
\hline & 70_8 & 0.6705 & 0.01324 & 0.9878 & 0.06406 & 0.05103 \\
\hline & 70_9 & 0.6914 & 0.01286 & 0.9878 & 0.06602 & 0.05290 \\
\hline & 70_10 & 0.6636 & 0.01376 & 0.9860 & 0.07202 & 0.05885 \\
\hline
\end{tabular}

The values of the Biot numbers obtained as a result of optimization for the temperature of $40{ }^{\circ} \mathrm{C}$ (ID 40_1-40_5) are within the range of 0.723-0.755; for $50^{\circ} \mathrm{C}$ (ID 50_1-50_3), are within the range of $0.701-0.725$; for $60{ }^{\circ} \mathrm{C}$ (ID 60_1-60_4), are within the range of 0.700-0.709; for $70{ }^{\circ} \mathrm{C}$ (ID 70_1-70_3), are within the range of $0.700-0.701$; and including the MAE criterion (ID 70_1-70_5), are within the range of 0.679-0.701. The smallest RMSE (0.0373) and MAE (0.0323) were obtained for $T=50{ }^{\circ} \mathrm{C}$, whereas the greatest errors for were obtained for $T=40{ }^{\circ} \mathrm{C}$. The results of optimization indicate that, initially, the Biot number does not change (or changes slightly) with the increase of temperature $\left(40-50{ }^{\circ} \mathrm{C}\right.$ ), followed by the decrease in its value $\left(50-70{ }^{\circ} \mathrm{C}\right)$. The obtained results of optimization also indicate that the increase of $T$ results in the increase of the moisture diffusion coefficient (i.e., [26,28]) (Table 2). 


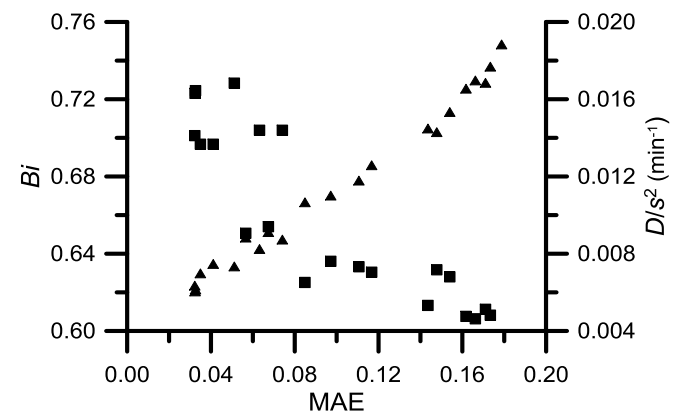

(a)

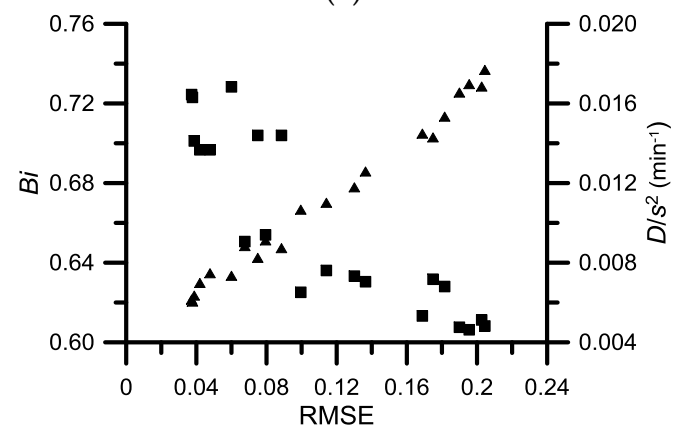

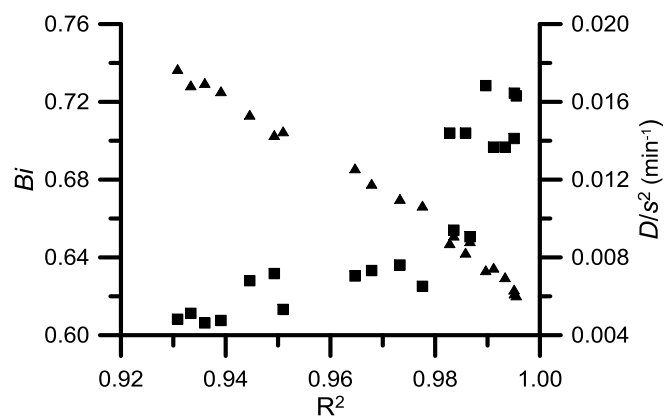

(b)

(c)

Figure 2. Pareto optimal set for the Biot number $(\boldsymbol{\square})$ and $D / s^{2}(\mathbf{\Lambda})$ for $T=50^{\circ} \mathrm{C}$.

In accordance with Equations (5)-(7), the value of the calculated reduced moisture content MR depends not only on the Biot number, but also, assuming the accuracy of the description by the model, on the moisture diffusion coefficient $D$. Figure 2 shows an example of the relation between $B i$ and the moisture diffusion coefficient. The increase of the Biot number requires the value of $D$ to be reduced (Figure 2), with better fitting of the model (5) to experimental data being obtained for greater Bi values. For smaller values of $B i$, the errors (RMSE and MAE) are greater, and $R^{2}$ is smaller, even after the increase of $D$ (Figure 2).

\subsection{Case 2a. Optimization of Parameters of the Function for Determining the Biot Number (Equation (8a))}

The optimization task described by Equation (10) considers the Biot number from Equation (8a) in $M R_{\text {pred }}$ (Equations (5)-(7)). Therefore, the parameters $a_{b}$ and $b_{b}$ of the equation (Equation (8a)) were sought in this strategy.

The results of optimization are presented in Table 3, Figure 3, and Figure 4. The best solution is ID 2a_1 (the smallest MAE $=0.05346$ and the greatest $R^{2}=0.9822$ ) and ID 2a_2 (the smallest RMSE $=0.06695$ and slightly worse MAE and $R^{2}$ compared with ID 2a_1).

Table 3. Pareto optimal set for constants in Equations (8a) and (9) and results of the statistical analysis.

\begin{tabular}{cccccccc}
\hline ID & $\boldsymbol{a}_{\boldsymbol{b}}$ & $\boldsymbol{b}_{\boldsymbol{b}}$ & $\boldsymbol{a}_{\boldsymbol{d}}$ & $\boldsymbol{b}_{\boldsymbol{d}}$ & $\boldsymbol{R}^{\mathbf{2}}$ & $\mathrm{RMSE}$ & MAE \\
\hline 2a_1 & 0.81932 & 6.49505 & 0.00704 & 2.54000 & 0.9822 & 0.06724 & 0.05346 \\
2a_2 & 0.81976 & 6.53818 & 0.00720 & 2.54000 & 0.9817 & 0.06695 & 0.05358 \\
2a_3 & 0.81935 & 6.48207 & 0.00717 & 2.28576 & 0.9815 & 0.06717 & 0.05374 \\
2a_4 & 0.81959 & 6.43306 & 0.00722 & 2.06814 & 0.9812 & 0.06744 & 0.05405 \\
2a_5 & 0.82018 & 6.47067 & 0.00700 & 1.57058 & 0.9814 & 0.06783 & 0.05405 \\
2a_6 & 0.82042 & 6.47042 & 0.00705 & 1.57079 & 0.9813 & 0.06779 & 0.05411 \\
2a_7 & 0.81959 & 6.43306 & 0.00722 & 1.56814 & 0.9807 & 0.06804 & 0.05455 \\
2a_8 & 0.81964 & 6.52297 & 0.00732 & 1.91671 & 0.9807 & 0.06794 & 0.05457 \\
2a_9 & 0.81955 & 6.46056 & 0.00735 & 1.58362 & 0.9803 & 0.06864 & 0.05514 \\
2a_10 & 0.81958 & 6.45445 & 0.00750 & 1.87225 & 0.9800 & 0.06911 & 0.05557 \\
\hline
\end{tabular}




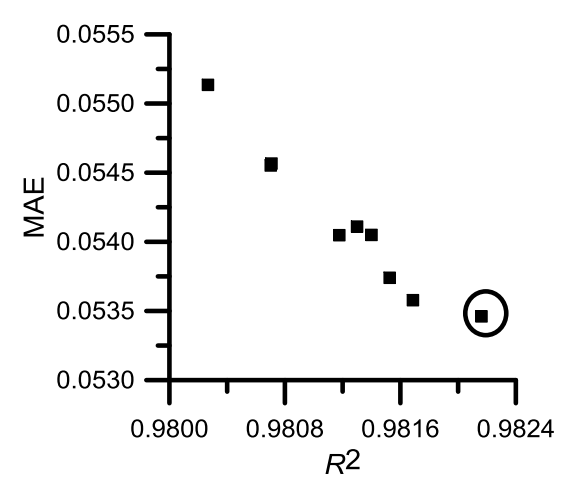

(a)

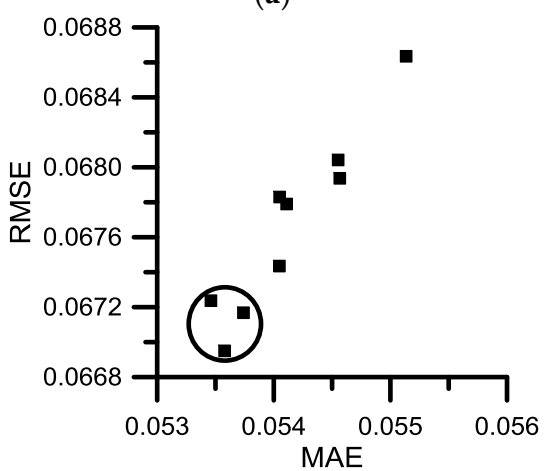

(c)

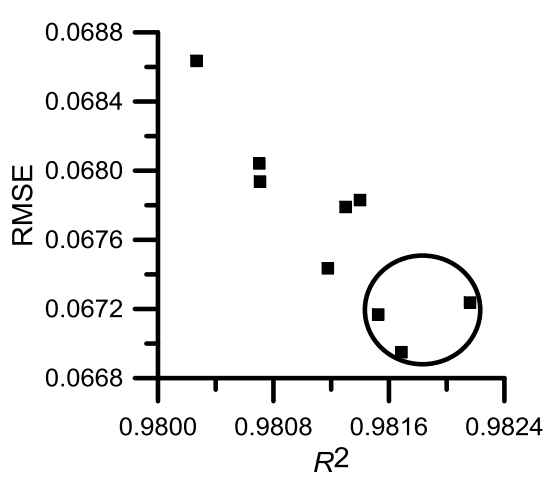

(b)

Figure 3. Pareto optimal sets for constants of Equation (8a).

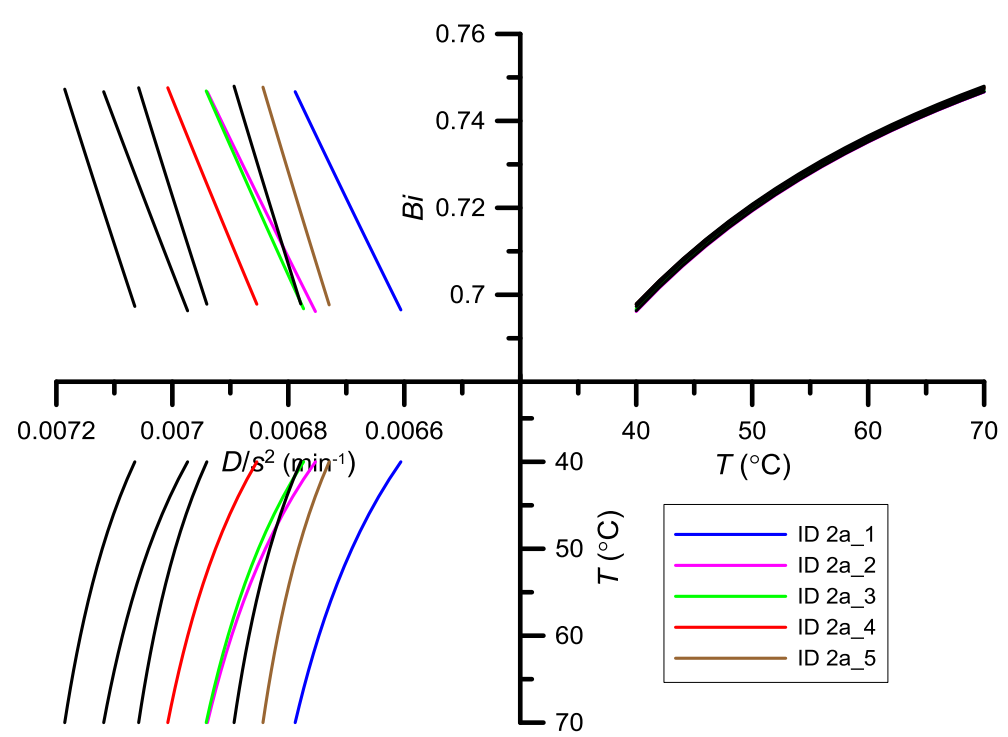

Figure 4. Pareto optimal set for the function of the Biot number and $D / s^{2}$ : Equations (8a) and (9).

The courses of the function (Equation (8a)) with parameters $a_{b}$ and $b_{b}$ obtained as a result of optimization are very similar (Figure 5) (overlap almost entirely-similar values of parameters (Table 3)), and the values of the Biot number obtained from them for the temperatures of $40-70^{\circ} \mathrm{C}$ are within the range of $0.696523-0.74672$ for ID 2a_1 and 0.696144-0.746659 for ID 2a_2. The courses of the function (Equation (9)) with parameters $a_{d}$ and $b_{d}$ obtained as a result of optimization differ from each other (Figure 4 ) and the best solution of the optimization task was obtained for smaller values of the moisture diffusion coefficient. The values of $D / s^{2}$ for the temperatures of $40-70^{\circ} \mathrm{C}$ are within the range of 0.006606-0.006788 for ID 2a_1 and 0.006753-0.00694 for ID 2a_2. 


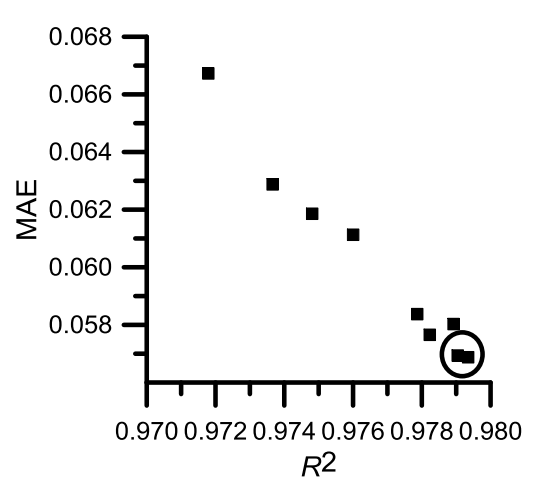

(a)

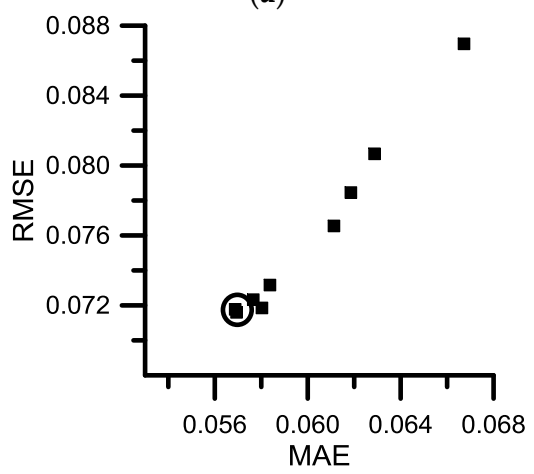

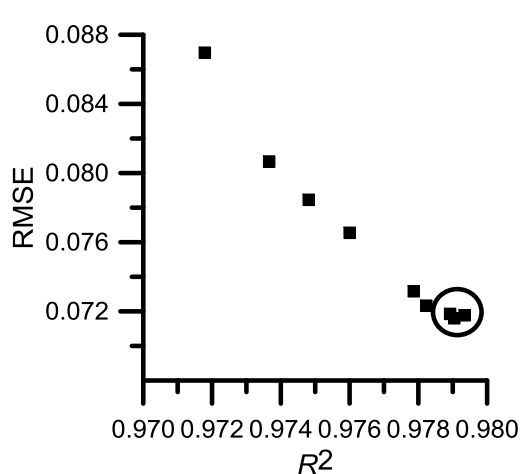

(b)

(c)

Figure 5. Pareto optimal sets for constants of Equation (8b).

3.3. Case 2b. Optimization of Parameters of the Function for Determining the Biot number (Equation (8b))

The results of optimization are presented in Table 4 and Figures 5 and 6 . The best solutions are ID $2 b \_1$ (the smallest MAE $=0.05688$ and the greatest $R^{2}=0.9794$ ) and ID 2b_2 (the smallest RMSE = 0.07160 and slightly smaller $R^{2}$ (difference 0.0004$)$ ).

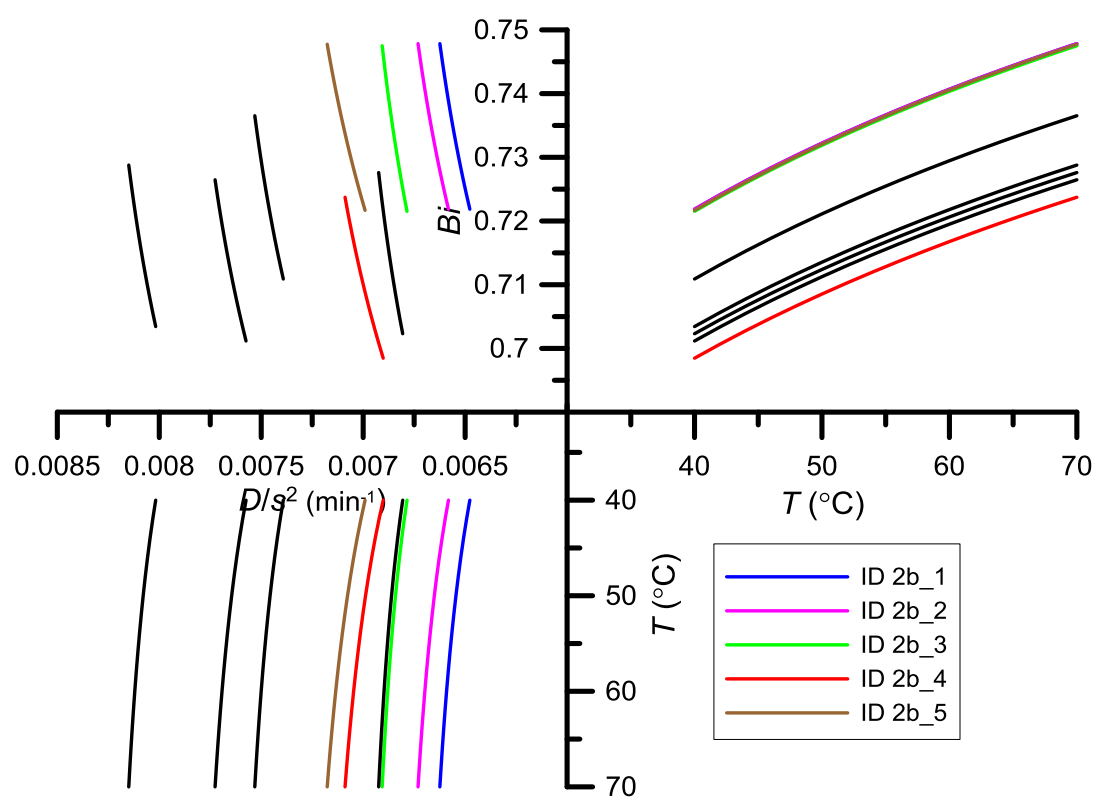

Figure 6. Pareto optimal set for the function of the Biot number and $D / s^{2}$ : Equations (8b) and (9).

The courses of the function (Equation (8b)) with parameters $a_{b}$ and $b_{b}$ obtained as a result of optimization are very similar (Figure 6) (ID 2b_1, 2b_2, and 2b_3 overlap almost entirely - similar 
values of parameters (Table 4)), and the values of the Biot numbers obtained from the function for the temperatures of $40-70{ }^{\circ} \mathrm{C}$ are within the range of $0.721854-0.747842$ both for ID $2 b \_1$ and ID 2b_2, and they are the greatest compared with the other solutions. The courses of the function (Equation (9)) with parameters $a_{d}$ and $b_{d}$ obtained as a result of optimization differ from each other (Figure 6) and the best solution of the optimization task was obtained for smaller values of the moisture diffusion coefficient. The values of $D / s^{2}$ for the temperatures of $40-70^{\circ} \mathrm{C}$ are within the range of $0.006477-0.006624$ for ID 2b_1 and 0.006582-0.006731 for ID 2b_2.

Table 4. Pareto optimal set for constants in Equations (8b) and (9) and results of the statistical analysis.

\begin{tabular}{cccccccc}
\hline ID & $\boldsymbol{a}_{\boldsymbol{b}}$ & $\boldsymbol{b}_{\boldsymbol{b}}$ & $\boldsymbol{a}_{\boldsymbol{d}}$ & $\boldsymbol{b}_{\boldsymbol{d}}$ & $\boldsymbol{R}^{\mathbf{2}}$ & RMSE & MAE \\
\hline 2b_1 & 0.04644 & 140795.3 & 0.006825 & 2.094928 & 0.9794 & 0.07178 & 0.05688 \\
2b_2 & 0.04644 & 140795.5 & 0.006935 & 2.091899 & 0.9790 & 0.07160 & 0.05694 \\
2b_3 & 0.046449 & 139323 & 0.007073 & 1.661161 & 0.9782 & 0.07233 & 0.05766 \\
2b_4 & 0.045152 & 130655.1 & 0.007347 & 2.498029 & 0.9789 & 0.07185 & 0.05803 \\
2b_5 & 0.046592 & 133294.6 & 0.007432 & 2.446309 & 0.9779 & 0.07316 & 0.05837 \\
2b_6 & 0.045209 & 139490.1 & 0.007085 & 1.60367 & 0.9760 & 0.07654 & 0.06113 \\
2b_7 & 0.045793 & 138027.1 & 0.007722 & 1.747985 & 0.9748 & 0.07845 & 0.06186 \\
2a_8 & 0.045224 & 135305.8 & 0.007933 & 1.8519 & 0.9737 & 0.08067 & 0.06288 \\
2a_9 & 0.045296 & 138802.9 & 0.008329 & 1.525632 & 0.9718 & 0.08710 & 0.06673 \\
2b_10 & 0.046629 & 139913.5 & 0.008114 & 1.605228 & 0.9718 & 0.08986 & 0.06883 \\
\hline
\end{tabular}

\subsection{Case 2c. Optimization of Parameters of the Function for Determining the Biot Number (Equation (8c))}

The results of optimization are presented in Table 5 and Figures 7 and 8 . The best solutions are ID 2c $\_1$ (the smallest MAE $=0.05693$ and the greatest $R^{2}=0.9793$ ) and ID 2c $\_2$ (the smallest RMSE = 0.07168843 and slightly smaller $R^{2}$ (difference 0.0003 )).

Table 5. Pareto optimal set for constants in Equations (8c) and (9) and results of the statistical analysis.

\begin{tabular}{cccccccc}
\hline ID & $\boldsymbol{a}_{\boldsymbol{b}}$ & $\boldsymbol{b}_{\boldsymbol{b}}$ & $\boldsymbol{a}_{\boldsymbol{d}}$ & $\boldsymbol{b}_{\boldsymbol{d}}$ & $\boldsymbol{R}^{\mathbf{2}}$ & RMSE & MAE \\
\hline 2c_1 & 0.105914 & 161892.9 & 0.006818 & 1.999354 & 0.9793 & 0.07184 & 0.05693 \\
2c_2 & 0.105920 & 161892.9 & 0.006939 & 1.999354 & 0.9790 & 0.07168 & 0.05701 \\
2c_3 & 0.105956 & 161896.9 & 0.007083 & 1.836184 & 0.9784 & 0.07212 & 0.05751 \\
2c_4 & 0.105896 & 162115 & 0.007115 & 1.717303 & 0.9782 & 0.07242 & 0.05773 \\
2c_5 & 0.105920 & 161892.9 & 0.007259 & 1.999354 & 0.9780 & 0.07274 & 0.05803 \\
2c_6 & 0.102556 & 162170.2 & 0.007465 & 1.623216 & 0.9777 & 0.07301 & 0.05877 \\
2c_7 & 0.102552 & 162127.3 & 0.007589 & 1.80125 & 0.9775 & 0.07331 & 0.05887 \\
2c_8 & 0.102543 & 162188.4 & 0.007620 & 1.608689 & 0.9772 & 0.07384 & 0.05919 \\
2c_9 & 0.102548 & 162077.8 & 0.007761 & 1.823051 & 0.9770 & 0.07446 & 0.05951 \\
2c_10 & 0.103676 & 162170.9 & 0.007290 & 1.999114 & 0.9765 & 0.07493 & 0.05968 \\
\hline
\end{tabular}

The courses of the function (Equation (8c)) with parameters $a_{b}$ and $b_{b}$ obtained as a result of optimization are very similar (Figure 8) (overlap almost entirely-similar values of parameters (Table 5)), and the values of the Biot numbers obtained from the function for the temperatures of $40-70^{\circ} \mathrm{C}$ are within the range of $0.721413-0.747151$ for ID 2c_1 and 0.721450-0.747192 for ID 2c_2, and they are the greatest compared with other solutions. The courses of the function (Equation (9)) with parameters $a_{d}$ and $b_{d}$ obtained as a result of optimization differ from each other (Figure 8) and the best solution of the optimization task was obtained for smaller values of the moisture diffusion coefficient. The values of $D / s^{2}$ for the temperatures of $40-70^{\circ} \mathrm{C}$ are within the range of $0.00649-0.00663$ for ID 2c_1 and $0.0066-0.00674$ for ID 2c_2. 


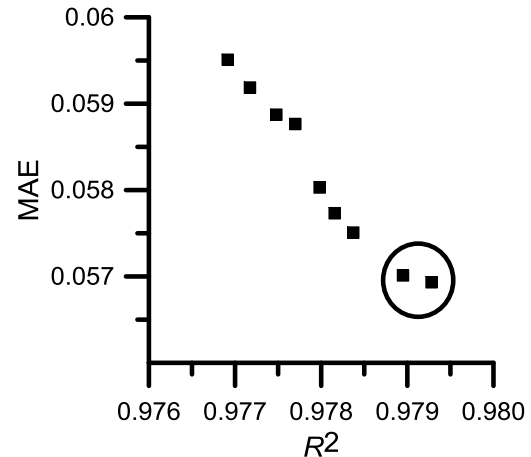

(a)

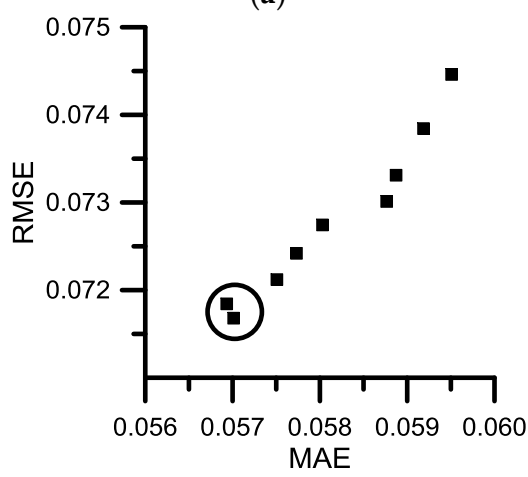

(c)

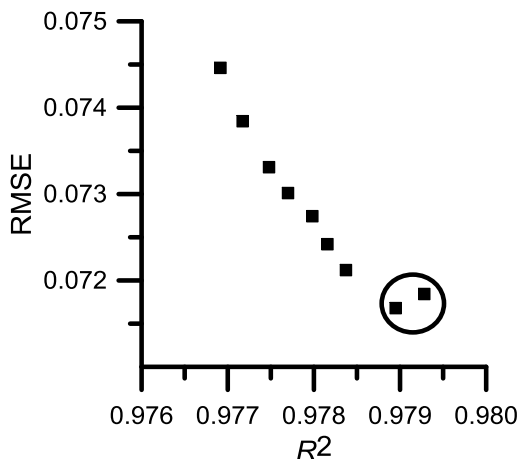

(b)

Figure 7. Pareto optimal sets for constants of Equation (8c).

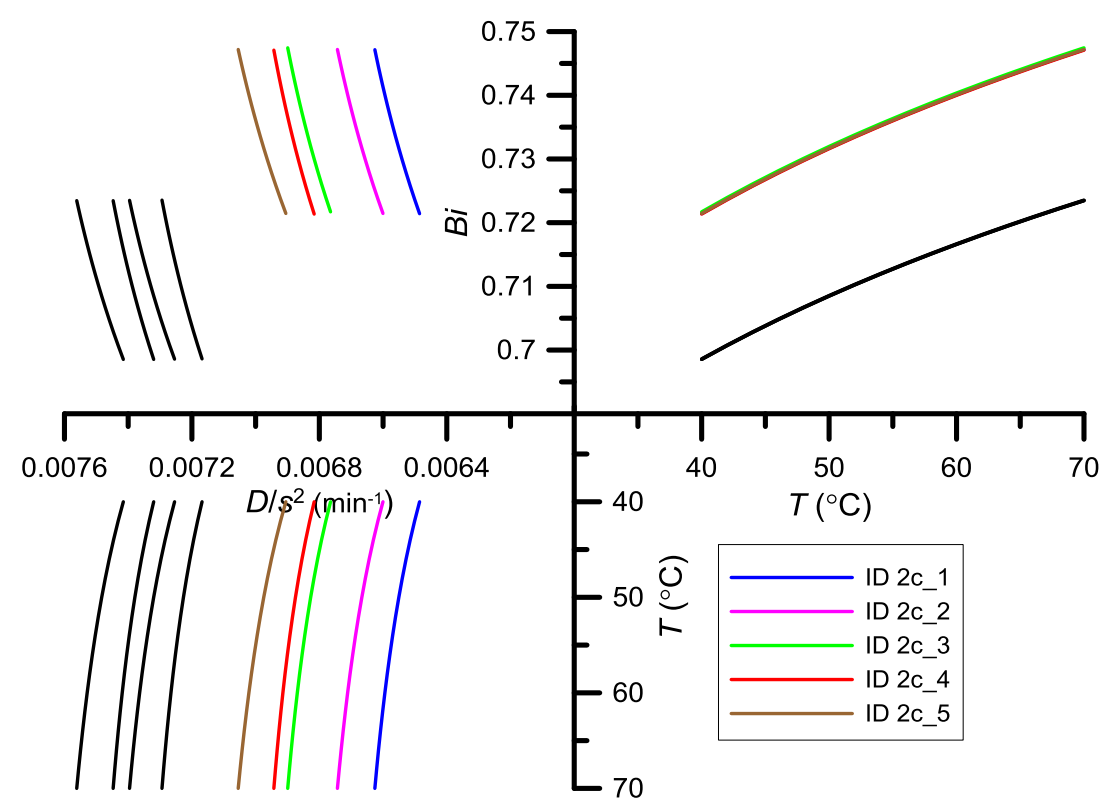

Figure 8. Pareto optimal set for the function of the Biot number and $D / s^{2}$ : Equations (8c) and (9).

\subsection{Case 2d. Optimization of Parameters of the Function for Determining the Biot Number (Equation (8d))}

The results of optimization are presented in Table 6 and Figures 9 and 10. The performed optimization also allowed us to obtain constants for Equation (8d) and Equation (9) and then to calculate the Biot number and the moisture diffusion coefficient (Table 6). The best solutions are ID 2d_1 (the smallest MAE $=0.05378$ and the greatest $R^{2}=0.9818$ ) and ID 2d_2 (the smallest RMSE = 0.06742 and only slightly worse $R^{2}$ (difference 0.0004 )). 
Table 6. Pareto optimal set for constants in Equations (8d) and (9) and results of the statistical analysis.

\begin{tabular}{cccccccc}
\hline ID & $\boldsymbol{a}_{\boldsymbol{b}}$ & $\boldsymbol{b}_{\boldsymbol{b}}$ & $\boldsymbol{a}_{\boldsymbol{d}}$ & $\boldsymbol{b}_{\boldsymbol{d}}$ & $\boldsymbol{R}^{\mathbf{2}}$ & RMSE & MAE \\
\hline 2d_1 & 0.087671 & 0.374624 & 0.006984 & 1.988010 & 0.9818 & 0.06763 & 0.05378 \\
2d_2 & 0.087777 & 0.374868 & 0.007130 & 1.988010 & 0.9814 & 0.06742 & 0.05390 \\
2d_3 & 0.099520 & 0.329786 & 0.007546 & 2.461728 & 0.9804 & 0.06837 & 0.05507 \\
2d_4 & 0.091440 & 0.359263 & 0.007757 & 2.217054 & 0.9794 & 0.07085 & 0.05688 \\
2d_5 & 0.100428 & 0.303184 & 0.008240 & 2.052006 & 0.9783 & 0.07329 & 0.05852 \\
2d_6 & 0.091342 & 0.356587 & 0.007770 & 2.413837 & 0.9778 & 0.07300 & 0.05883 \\
2d_7 & 0.078979 & 0.400324 & 0.007770 & 1.930612 & 0.9773 & 0.07414 & 0.05956 \\
2d_8 & 0.072832 & 0.412350 & 0.007200 & 1.973931 & 0.9772 & 0.07705 & 0.06194 \\
2d_9 & 0.077064 & 0.381598 & 0.008456 & 2.366783 & 0.9758 & 0.07764 & 0.06241 \\
2d_10 & 0.029274 & 0.581316 & 0.008014 & 1.660092 & 0.9746 & 0.07869 & 0.06313 \\
\hline
\end{tabular}

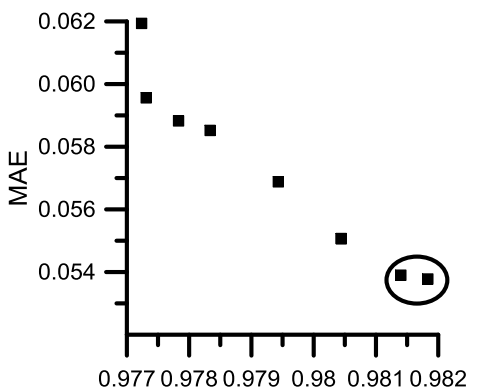

$\mathrm{R}^{2}$

(a)

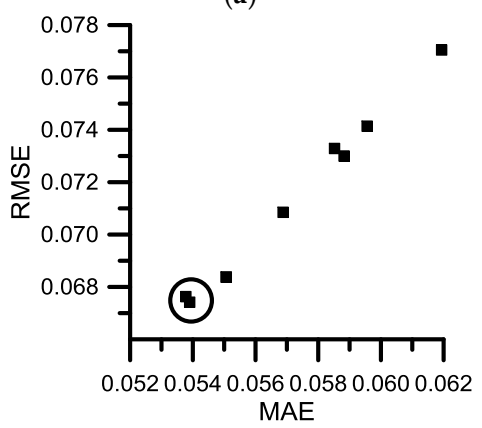

(c)

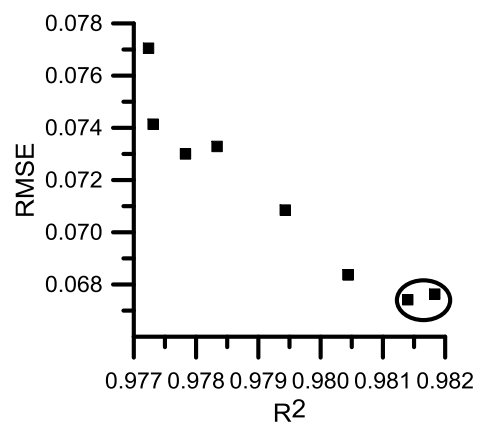

(b)

Figure 9. Pareto optimal sets for constants of Equation (8d).

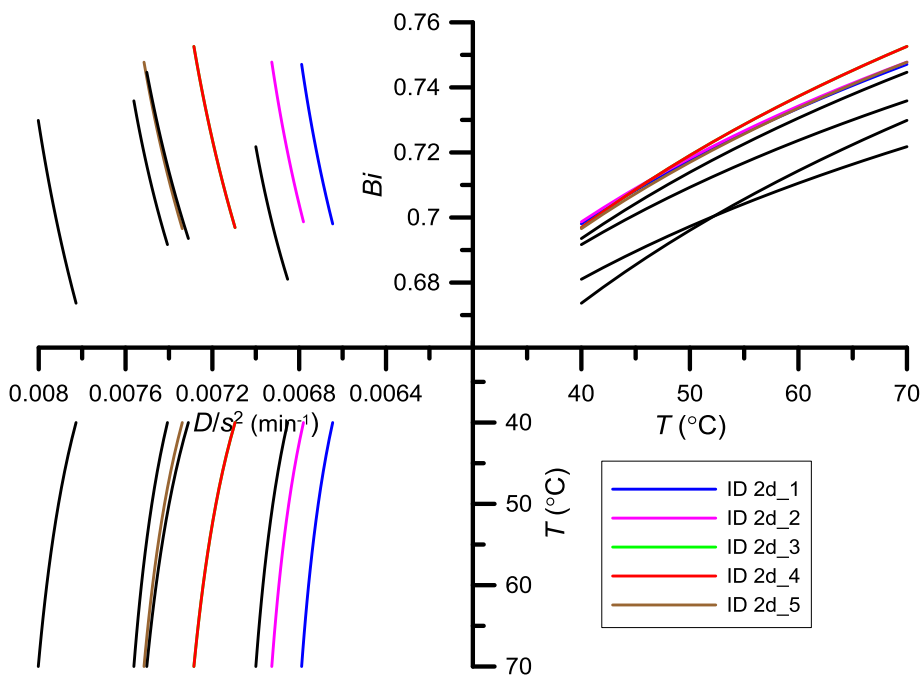

Figure 10. Pareto optimal set for the function of the Biot number and $D / s^{2}$ : Equations (8d) and (9). 
The courses of the function (Equation (8d)) with parameters $a_{b}$ and $b_{b}$ obtained as a result of optimization are very similar (Figure 10) (overlap almost entirely-similar values of parameters (Table 6)), and the values of the Biot numbers obtained from the function for the temperatures of $40-70{ }^{\circ} \mathrm{C}$ are within the range of $0.698032-0.747095$ for ID $2 \mathrm{~d} \_1$ and $0.698668-0.747789$ for ID 2d_2, and are the greatest compared with other solutions. The courses of the function (Equation 9) with parameters $a_{d}$ and $b_{d}$ obtained as a result of optimization differ from each other (Figure 10) and the best solution of the optimization task was obtained for smaller values of the moisture diffusion coefficient. The values of $D / s^{2}$ for the temperatures of $40-70^{\circ} \mathrm{C}$ are within the range of $0.00665-0.00679$ for ID $2 \mathrm{~d} \_1$ and 0.00678-0.00693 for ID 2d_2.

\subsection{Case 2e. Optimization of Parameters of the Function for Determining the Biot Number (Equation (8e))}

The results of optimization are presented in Table 7 and Figures 11 and 12. The optimization also allowed us to obtain constants Equation (8e) and Equation (9) and then to calculate the Biot number and the moisture diffusion coefficient (Table 7). The set of best solutions is made up of ID 2e_1-ID 2e_5, with ID 2e_1 being characterised by the smallest value of MAE $=0.06633$, ID 2e_4 by the smallest value of RMSE $=0.08183$, and ID 2e_5 by the greatest $R^{2}=0.9771$. For ID 2e_1, RMSE is greater than for ID $2 \mathrm{e} \_4$ by only 0.0002 and $R^{2}$ is smaller than for ID $2 \mathrm{e} \_5$ by only 0.0003 . For ID $2 \mathrm{e} \_4$, MAE is greater than for ID 2e_1 by only 0.0002 and $R^{2}$ is only 0.0003 smaller than for ID 2e_5. For ID 2e_5, MAE is greater than for ID 2e_1 by only 0.0002 and RMSE is greater than for ID 2e_4 by only 0.00006 . For ID 2e_2, ID 2e_3, and ID 2e_6, $R^{2}$ is smaller than the greatest one (ID 2e_5) by 0.0002, 0.00007, and 0.0001 , respectively; RMSE is greater than the smallest one (ID 2e_4) by $0.00013,0.00014$, and 0.000005 , respectively; and MAE is greater than the smallest one (ID 2e_1) by $0.00001,0.0009$, and 0.00025 , respectively.

Table 7. Pareto optimal set for constants in Equations (8e) and (9) and results of the statistical analysis.

\begin{tabular}{cccccccc}
\hline ID & $\boldsymbol{a}_{\boldsymbol{b}}$ & $\boldsymbol{b}_{\boldsymbol{b}}$ & $\boldsymbol{a}_{\boldsymbol{d}}$ & $\boldsymbol{b}_{\boldsymbol{d}}$ & $\boldsymbol{R}^{\mathbf{2}}$ & RMSE & MAE \\
\hline 2e_1 & 1.298971 & 0.124544 & 0.006152 & 4.960183 & 0.9768 & 0.08207 & 0.06633 \\
2e_2 & 1.449848 & 0.153382 & 0.006185 & 4.996656 & 0.9769 & 0.08196 & 0.06634 \\
2e_3 & 1.290019 & 0.131396 & 0.006165 & 4.989554 & 0.9770 & 0.08197 & 0.06642 \\
2e_4 & 1.289663 & 0.129626 & 0.006287 & 4.989283 & 0.9768 & 0.08183 & 0.06651 \\
2e_5 & 1.456449 & 0.165094 & 0.006188 & 4.984513 & 0.9771 & 0.08189 & 0.06652 \\
2e_6 & 1.466073 & 0.166745 & 0.006246 & 4.961883 & 0.9770 & 0.08184 & 0.06658 \\
2a_7 & 1.557768 & 0.172773 & 0.006043 & 3.882209 & 0.9762 & 0.08287 & 0.06694 \\
2e_8 & 1.562403 & 0.184398 & 0.006047 & 3.886745 & 0.9765 & 0.08278 & 0.06715 \\
2e_9 & 1.56531 & 0.183702 & 0.006119 & 3.888001 & 0.9763 & 0.08269 & 0.06719 \\
2e_10 & 1.276498 & 0.120256 & 0.005896 & 2.895483 & 0.9756 & 0.08381 & 0.06743 \\
\hline
\end{tabular}

The courses of the function (Equation (8e)) with parameters $a_{b}$ and $b_{b}$ obtained as a result of optimization differ from each other (Figure 12), and the values of $B i$ obtained from them are the greatest. The values of $B i$ obtained for the temperatures of $40-70{ }^{\circ} \mathrm{C}$ are within the range of 0.823371-0.721929: $0.820488-0.76525$ for ID 2e_1, 0.823371-0.755645 for ID 2e_2, 0.794496-0.738172 for ID 2e_3, 0.79948-0.743539 for ID 2e_4, 0.792145-0.722239 for ID 2e_5, and 0.792538-0.721929 for ID 2e_6. The courses of the function (Equation (9)) with parameters $a_{d}$ and $b_{d}$ obtained as a result of optimization are similar (Figure 12) and the best solution of the optimization task was obtained for smaller values of the moisture diffusion coefficient (except for ID 2e_4). The values of $D / s^{2}$ obtained for the temperatures of $40-70^{\circ} \mathrm{C}$ are within the range of $0.00543-0.00573$ for ID 2e_1, 0.00546-0.00576 for ID 2e_2, 0.00544-0.00574 for ID 2e_3, 0.00555-0.00585 for ID 2e_4, 0.00546-0.00576 for ID 2e_5, and 0.00552-0.00582 for ID 2e_6. 


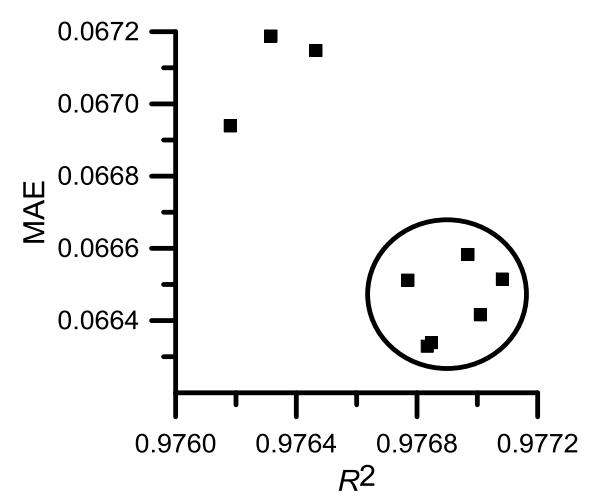

(a)

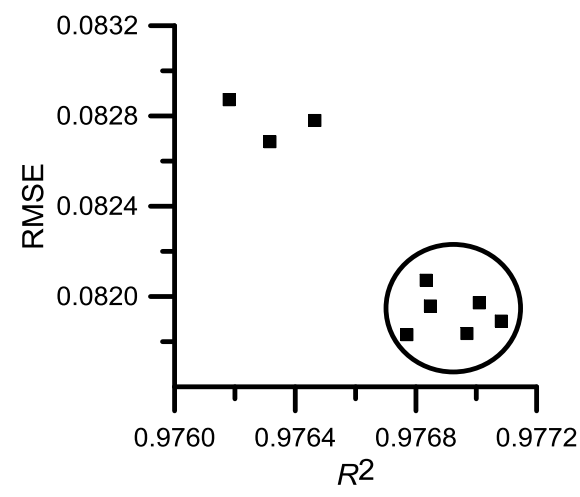

(b)

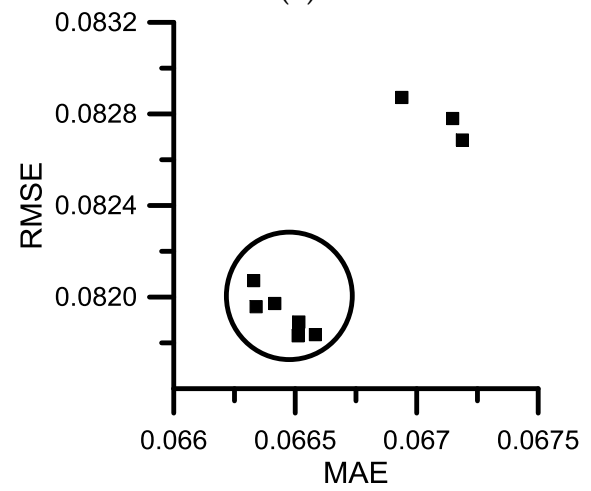

(c)

Figure 11. Pareto optimal sets for constants of Equation (8e).

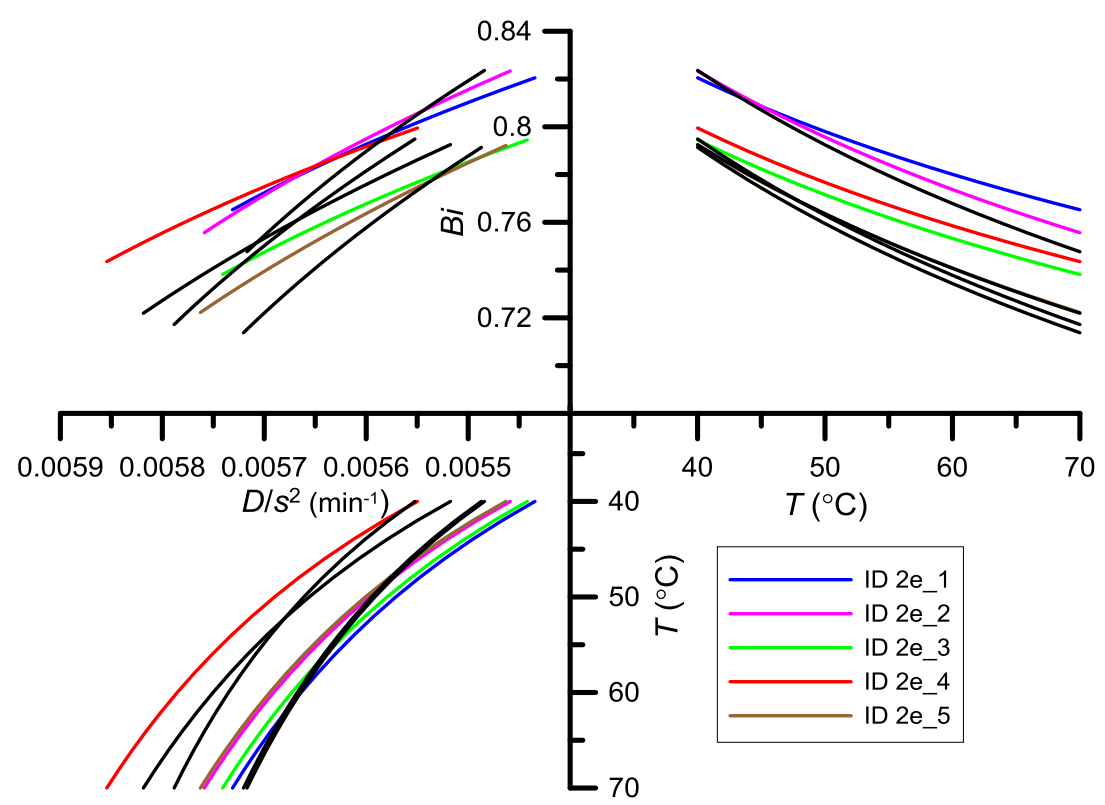

Figure 12. Pareto optimal set for the function of the Biot number and $D / s^{2}$ : Equations (8e) and (9).

3.7. Case 2f. Optimization of Parameters of the Function for Determining the Biot Number (Equation (8f))

The results of optimization are presented in Table 8 and Figures 13 and 14. The best solutions are ID 2f_1 (the smallest MAE $=0.06056$ and the greatest $R^{2}=0.9764$ ) and ID 2f_2 (the smallest RMSE = 0.07591 , and compared with 2f_1, slightly worse $R^{2}$ (smaller by 0.0002) and MAE (greater by 0.00002)) . 
Table 8. Pareto optimal set for constants in Equations (8f) and (9) and results of the statistical analysis.

\begin{tabular}{cccccccc}
\hline ID & $\boldsymbol{a}_{\boldsymbol{b}}$ & $\boldsymbol{b}_{\boldsymbol{b}}$ & $\boldsymbol{a}_{\boldsymbol{d}}$ & $\boldsymbol{b}_{\boldsymbol{d}}$ & $\boldsymbol{R}^{\mathbf{2}}$ & RMSE & MAE \\
\hline 2f_1 & 0.077244 & 862213.6 & 0.007368 & 5.739963 & 0.9764 & 0.07598 & 0.06056 \\
2f_2 & 0.077236 & 862220.8 & 0.007449 & 5.729922 & 0.9762 & 0.07591 & 0.06058 \\
2f_3 & 0.077207 & 864646.7 & 0.007868 & 5.355261 & 0.9748 & 0.07803 & 0.06199 \\
2f_4 & 0.073875 & 1059418 & 0.006741 & 2.720529 & 0.9745 & 0.07933 & 0.06235 \\
2a_5 & 0.077859 & 862396.3 & 0.007587 & 5.708511 & 0.9730 & 0.08043 & 0.06483 \\
2a_6 & 0.076727 & 865525.6 & 0.007648 & 4.417204 & 0.9713 & 0.08331 & 0.06520 \\
2f_7 & 0.078282 & 862213.6 & 0.007368 & 5.741489 & 0.9727 & 0.08254 & 0.06684 \\
2f_8 & 0.076328 & 960205.5 & 0.007648 & 2.969758 & 0.9698 & 0.08642 & 0.06705 \\
2f_9 & 0.072421 & 1059416 & 0.006582 & 1.131156 & 0.9690 & 0.08750 & 0.06884 \\
2f_10 & 0.070248 & 1137211 & 0.006003 & 0.042246 & 0.9696 & 0.08812 & 0.06893 \\
\hline
\end{tabular}

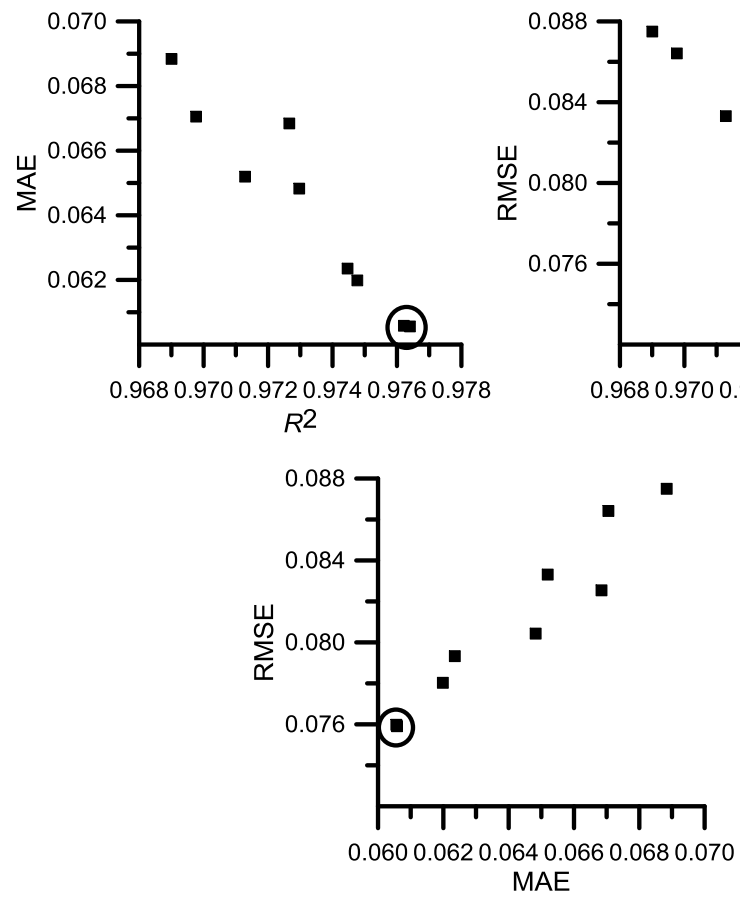

Figure 13. Pareto optimal sets for constants of Equation (8f).

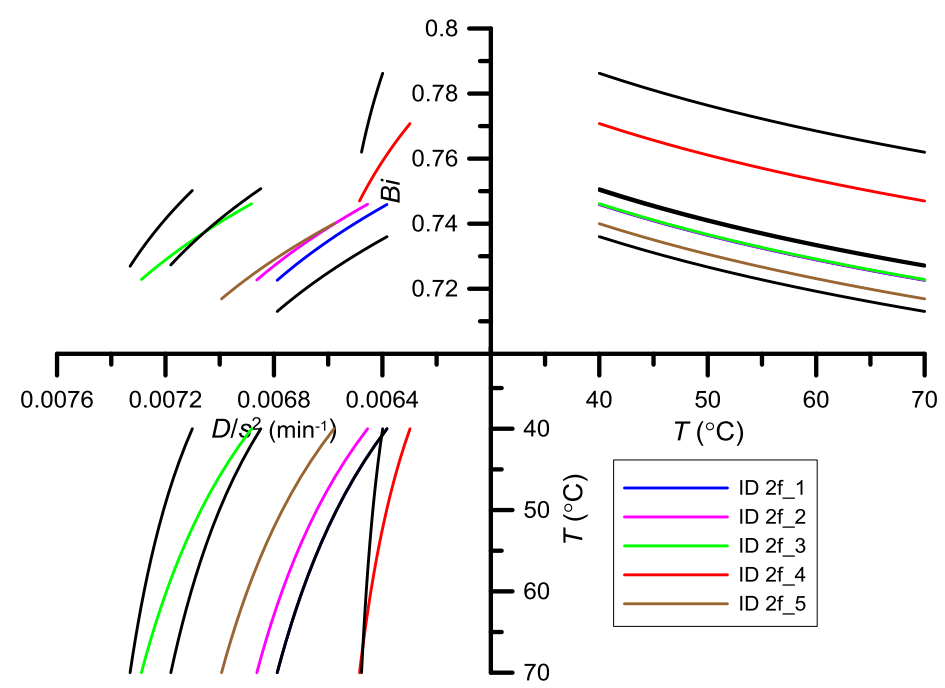

Figure 14. Pareto optimal set for the function of the Biot number and $D / s^{2}$ : Equations (8f) and (9). 
The courses of the function (Equation (8f)) with parameters $a_{b}$ and $b_{b}$ obtained as a result of optimization differ from each other (Figure 14). The values of the Biot number obtained for the temperatures of $40-70{ }^{\circ} \mathrm{C}$ are within the range of $0.745901-0.722602$ for ID 2f_1 and 0.745978-0.722677 for ID 2f_2. The courses of the function (Equation 9) with parameters $a_{d}$ and $b_{d}$ obtained as a result of optimization differ from each other (Figure 14). The values of $D / s^{2}$ obtained for the temperatures of $40-70{ }^{\circ} \mathrm{C}$ are within the range of $0.006383-0.006788$ for ID 2f_1 and $0.006454-0.006863$ for ID 2f_2.

\subsection{Case 2g. Optimization of Parameters of the Function for Determining the Biot Number (Equation (8g))}

The results of optimization are presented in Table 9 and Figure 15-16. The best solution is ID 2g_1 (the smallest both MAE $=0.06041$, RMSE $=0.07566$ and the greatest $R^{2}=0.9764$ ).

Table 9. Pareto optimal set for constants in Equations (8g) and (9) and results of the statistical analysis.

\begin{tabular}{cccccccc}
\hline ID & $\boldsymbol{a}_{\boldsymbol{b}}$ & $\boldsymbol{b}_{\boldsymbol{b}}$ & $\boldsymbol{a}_{\boldsymbol{d}}$ & $\boldsymbol{b}_{\boldsymbol{d}}$ & $\boldsymbol{R}^{\mathbf{2}}$ & RMSE & MAE \\
\hline 2g_1 & 0.17462 & 1193847 & 0.007492 & 5.999963 & 0.9764 & 0.07566 & 0.06041 \\
2g_2 & 0.17462 & 1193847 & 0.007492 & 4.984338 & 0.9754 & 0.07677 & 0.06124 \\
2g_3 & 0.20101 & 109835.1 & 0.007664 & 7.999996 & 0.9748 & 0.07827 & 0.06191 \\
2g_4 & 0.20101 & 109834.6 & 0.007698 & 7.999992 & 0.9747 & 0.07826 & 0.06192 \\
2g_5 & 0.20097 & 109790.8 & 0.007727 & 7.968262 & 0.9746 & 0.07830 & 0.06195 \\
2g_6 & 0.19994 & 114067.1 & 0.007438 & 6.988878 & 0.9743 & 0.07932 & 0.06265 \\
2g_7 & 0.18938 & 116127.4 & 0.007119 & 8.999996 & 0.9760 & 0.07926 & 0.06310 \\
2g_8 & 0.18938 & 116103.4 & 0.007247 & 8.999909 & 0.9758 & 0.07911 & 0.06312 \\
2g_9 & 0.18944 & 115792.8 & 0.007267 & 8.882749 & 0.9749 & 0.07991 & 0.06341 \\
2g_10 & 0.19830 & 114642.6 & 0.007446 & 5.755039 & 0.9731 & 0.08041 & 0.06346 \\
\hline
\end{tabular}

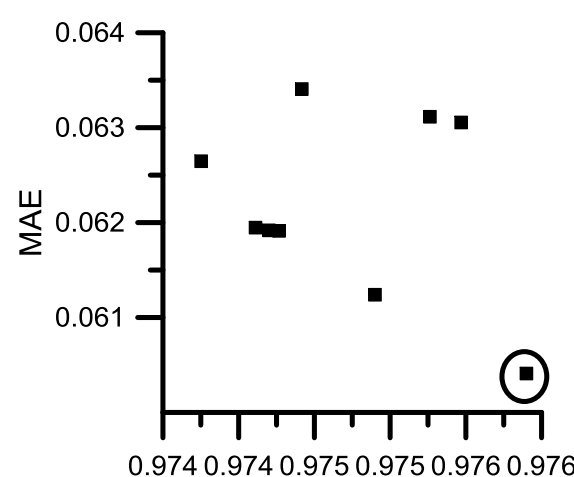

$R^{2}$

(a)

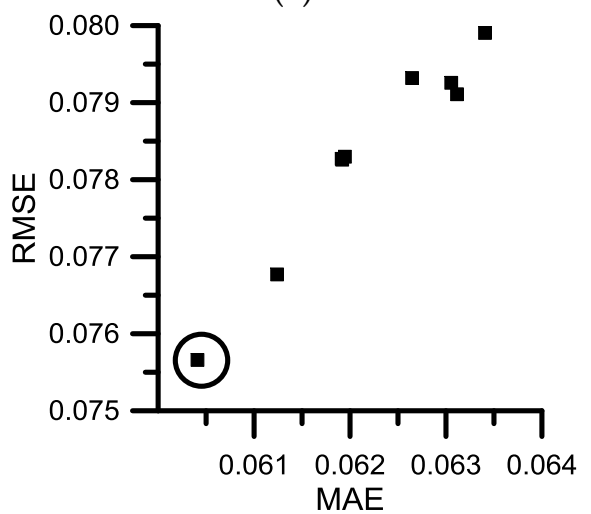

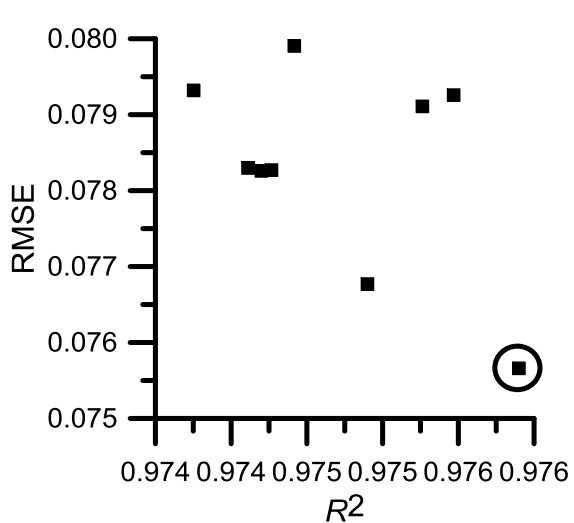

(b)

(c)

Figure 15. Pareto optimal sets for constants of Equation (8g). 
The courses of the function (Equation (8g)) with parameters $a_{b}$ and $b_{b}$ and the function (Equation (9)) with parameters $a_{d}$ and $b_{d}$ obtained as a result of optimization differ from each other (Figure 16). The values of the Biot number and the values of $D / s^{2}$ obtained for the temperatures of $40-70{ }^{\circ} \mathrm{C}$ for ID $2 \mathrm{~g} \_1$ change slightly and are within the range of $0.745762-0.722883$ and $0.006448-0.006877$, respectively.

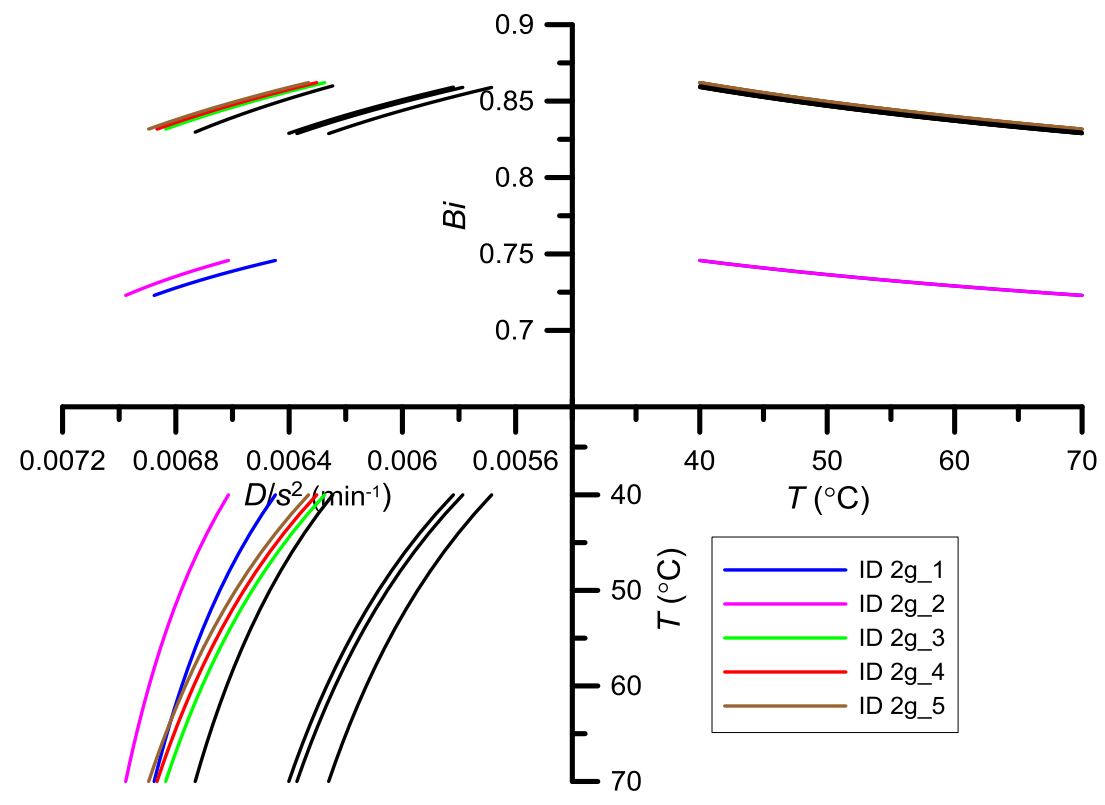

Figure 16. Pareto optimal set for the function of the Biot number and $D / s^{2}$ : Equations (8g) and (9).

3.9. Case 2h. Optimization of Parameters of the Function for Determining the Biot Number (Equation (8h))

The results of optimization are presented in Table 10 and Figures 17 and 18. The best solutions are ID 2h_1 (the smallest MAE $=0.06293$ and the greatest $R^{2}=0.9740$ ) and ID $2 \mathrm{~h} \_2$ (the smallest RMSE $=$ 0.07925 , with MAE being slightly worse than for ID 2h_1 (the difference 0.00003)).

Table 10. Pareto optimal set for constants in Equations (8h) and (9) and results of the statistical analysis.

\begin{tabular}{cccccccc}
\hline ID & $\boldsymbol{a}_{\boldsymbol{b}}$ & $\boldsymbol{b}_{\boldsymbol{b}}$ & $\boldsymbol{a}_{\boldsymbol{d}}$ & $\boldsymbol{b}_{\boldsymbol{d}}$ & $\boldsymbol{R}^{\mathbf{2}}$ & RMSE & MAE \\
\hline 2h_1 & 1.434697 & 2.507106 & 0.006923 & 2.14 & 0.9740 & 0.07927 & 0.06293 \\
2h_2 & 1.434897 & 2.509596 & 0.006967 & 2.14 & 0.9739 & 0.07925 & 0.06296 \\
2h_3 & 1.431146 & 2.528872 & 0.007108 & 2.13075 & 0.9736 & 0.07946 & 0.06315 \\
2h_4 & 1.431491 & 2.57301 & 0.007147 & 2.047283 & 0.9734 & 0.07970 & 0.06330 \\
2h_5 & 1.429736 & 2.524792 & 0.007201 & 2.118279 & 0.9733 & 0.07981 & 0.06337 \\
2h_6 & 1.429389 & 2.530306 & 0.007283 & 2.102477 & 0.9731 & 0.08025 & 0.06364 \\
2h_7 & 1.432067 & 2.515218 & 0.007349 & 2.128414 & 0.9729 & 0.08062 & 0.06385 \\
2h_8 & 1.430119 & 2.532143 & 0.007376 & 2.103931 & 0.9728 & 0.08085 & 0.06400 \\
2h_9 & 1.42891 & 2.540204 & 0.007397 & 2.086483 & 0.9727 & 0.08104 & 0.06412 \\
2h_10 & 1.435259 & 2.545177 & 0.007423 & 2.112372 & 0.9727 & 0.08118 & 0.06418 \\
\hline
\end{tabular}

The courses of the function (Equation (8h)) with parameters $a_{b}$ and $b_{b}$ obtained as a result of optimization differ slightly from each other (Figure 18). The values of the Biot number obtained for the temperatures of $40-70{ }^{\circ} \mathrm{C}$ are within the range of $0.742097-0.722428$ for ID $2 \mathrm{~h} \_1$ and within the range of $0.742039-0.722353$ for ID $2 \mathrm{~h} \_2$. The courses of the function (Equation (9)) with parameters $a_{d}$ and $b_{d}$ obtained as a result of optimization are similar (Figure 18) and the best solution of the optimization task was obtained for smaller values of the moisture diffusion coefficient. The values of $D / s^{2}$ obtained for the temperatures of $40-70{ }^{\circ} \mathrm{C}$ are within the range of $0.006562-0.006714$ for ID $2 \mathrm{~h} \_1$ and $0.006604-0.006757$ for ID 2h_2. 


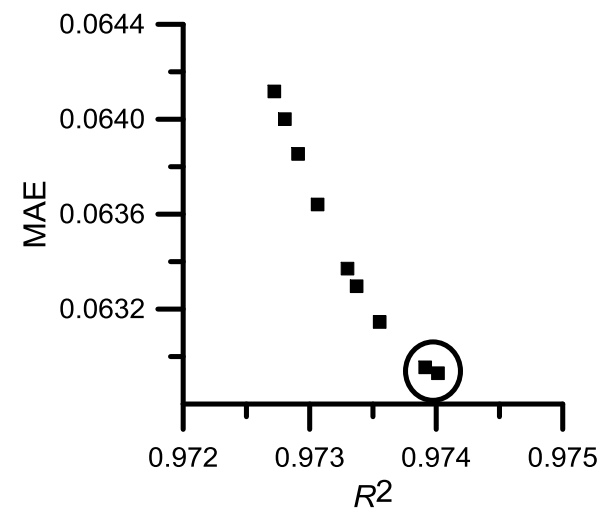

(a)

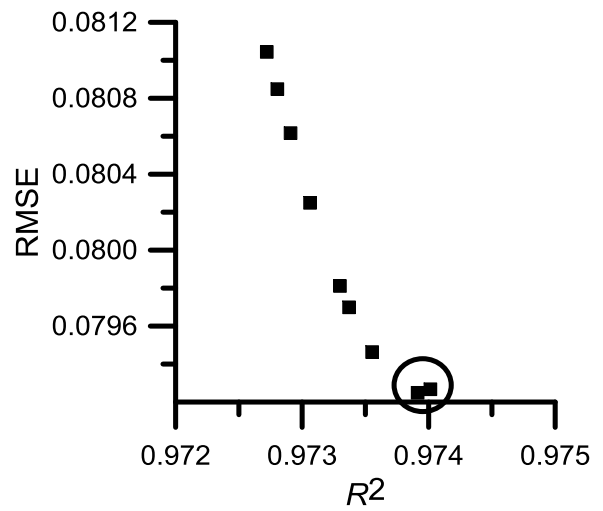

(b)

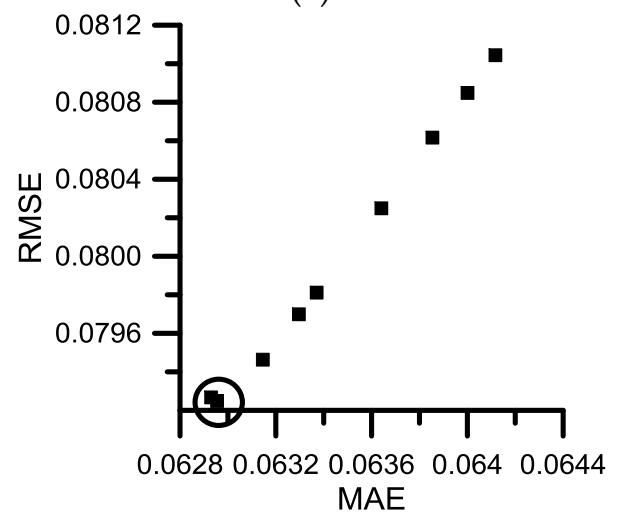

(c)

Figure 17. Pareto optimal sets for constants of Equation (8h).

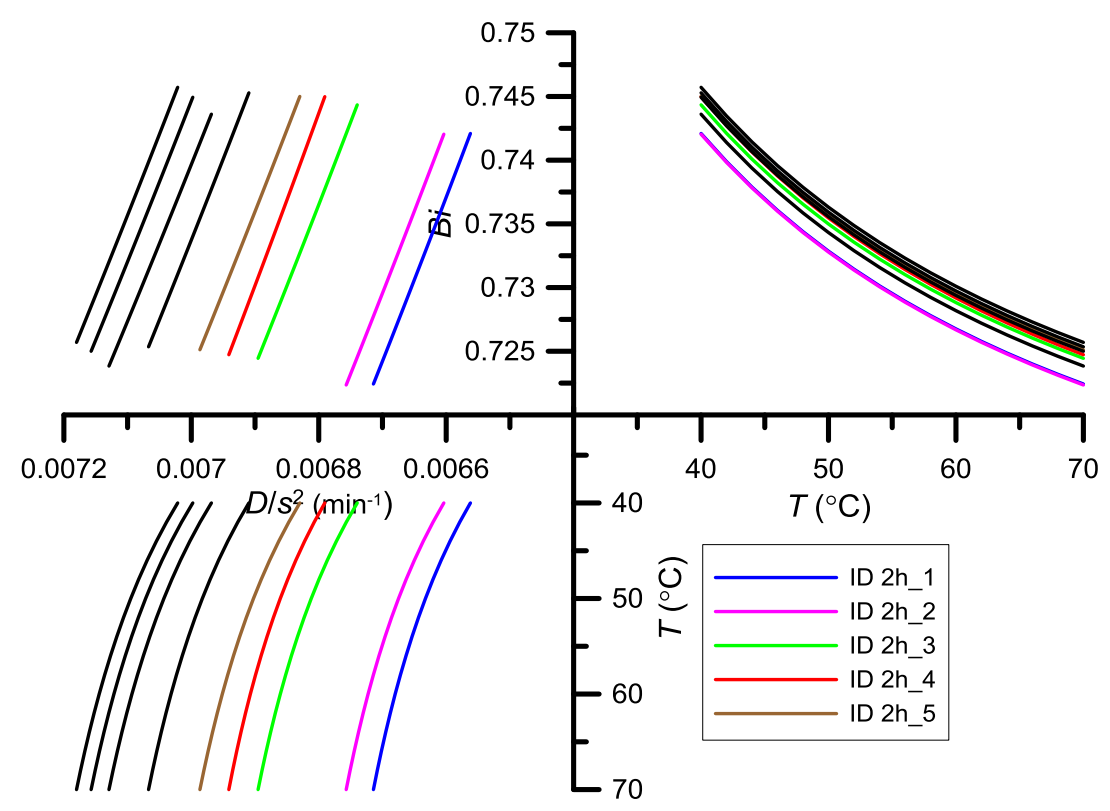

Figure 18. Pareto optimal set for the function of the Biot number and $D / s^{2}$ : Equations (8h) and (9).

Among the functions (Equation (8a))-(Equation (8d)) indicating the increase of the Biot number with the increase of the temperature, the best one was the function described by the equation (Equation (8a)), and the second best function (Equation (8d)) was only slightly worse. Among the functions (Equation (8e))-(Equation (8h)) indicating the decrease of the Biot number with the increase of the temperature, the best one was the function described by the equation (Equation (8g)), and the 
second best function (Equation (8h)) was only slightly worse. Figure 19 shows the Biot number and the moisture diffusion coefficient for the best solutions of the optimization task $2 \mathrm{a}, 2 \mathrm{~d}, 2 \mathrm{~g}$, and $2 \mathrm{~h}$.

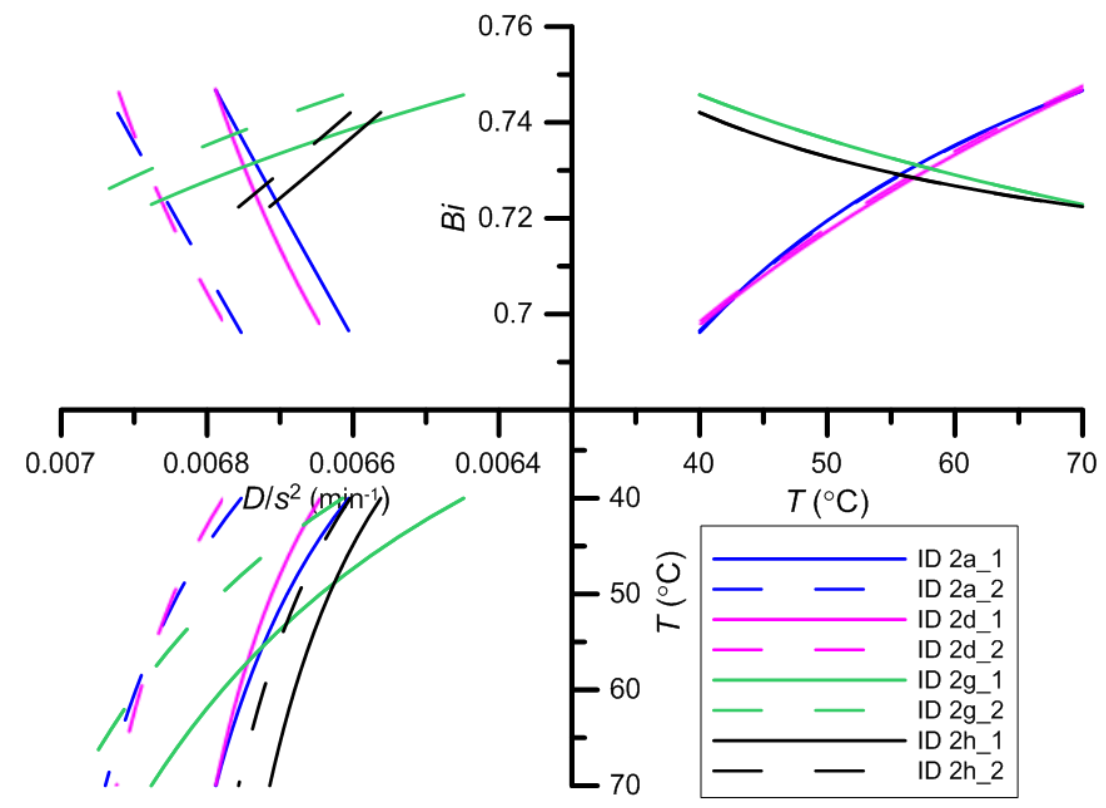

Figure 19. Pareto optimal set for the function of the Biot number and $D / s^{2}$ : Equations (8a), (8d), (8g), (8h), and (9).

The range of variability of the Biot number for ID 2a_1, 2a_2, and 2d_1 is identical (the courses of the functions are almost identical), and it ranges between 0.70 and 0.75 , whereas for ID $2 \mathrm{~g} \_1,2 \mathrm{~g} \_2,2 \mathrm{~h} \_1$, and $2 \mathrm{~h} \_2$, the range is smaller, between 0.72 and 0.75 . $D / s^{2}$ calculated using (Equation (9)) changes most for ID 2g_1 (0.00645-0.00688). For ID 2g_2, the changes are smaller (0.00661-0.00698), and for ID $2 \mathrm{a} \_2$ and $2 \mathrm{~d} \_2$, the changes are the smallest (the courses of the functions are almost identical), ranging between 0.00675 and 0.00685 .

According to (Equation (1)), the Biot number depends on the mass transfer coefficient $h_{m}$ and mass diffusion coefficient $D$. Therefore, the dependence of $B i$ on temperature is determined by the temperature influence on both mentioned coefficients. An increase of the temperature (according to the literature (i.e., Equation (9))) results in an increase of the moisture diffusion coefficient. In the definition of the Biot number (Equation (1)), there is a ratio $h_{m} / D$ and the Biot number depends precisely on this relation. A greater temperature impact on $h_{m}$ than on $D$ results in the increase of the Biot number with temperature. Many authors have applied a dimensionless number to estimate the value of the mass transfer coefficient $[8,24,29,30]$. Equation $S h=f(G r, S c)$ is often applied under natural convection conditions [31].

The dependences obtained as a result of optimization indicate that a better fitting of the model (5) to the experimental data is obtained when $B i$ increases with the increase of the drying temperature according to the (Equation (8a)) with the constants of the equation for ID 2a_1 (Table 3):

$$
B i=0.8193 \exp \left(-6.4951 T^{-1}\right),
$$

Simultaneously, $D / s^{2}$ is calculated based on (Equation (9)) with the constants of the equation for ID 2a_1 (Table 3):

$$
D / s^{2}=0.00704 \exp \left(-2.54 T^{-1}\right)
$$


However, only slightly worse fitting is obtained when $B i$ decreases with the increase of the drying temperature according to (Equation (8g)) with the constants of the equation for ID 2g_1 (Table 9):

$$
B i=1 / 0.1746 \log (119347 T)
$$

Simultaneously, $D / s^{2}$ is calculated based on (Equation (9)) with the constants of the equation for ID 2g_1 (Table 9):

$$
D / s^{2}=0.0075 \exp \left(-6 T^{-1}\right),
$$

The values of $D / s^{2}$ obtained from Equation (12) (for $40-70^{\circ} \mathrm{C}$ ) are the following: 0.00665-0.00679, and they are in the range of $0.00645-0.00688$ obtained from Equation (14). The $D$ values lie within the general range of $10^{13}$ to $10^{6} \mathrm{~m}^{2} \mathrm{~s}^{-1}$ for food materials [32,33]. However the range of the Biot number calculated from Equation (13) (0.7729-0.7458) is wider than that obtained from Equation (11) (0.6965-0.6747).

The acceptance in the drying model (Equation (5)) of the Biot number and $D / s^{2}$ determined from Equations (11) and (12) or from Equations (13) and (14) results in various fits of the discussed model at individual considered temperatures. The MAE values for the model (Equation (5)) $\left(B i\right.$ and $D / s^{2}$ from Equations (11) and (12)) are the following: 0.0690, 0.0340, 0.0426, and 0.0725 (for 40, 50, 60, and $70{ }^{\circ} \mathrm{C}$, respectively), whereas for $B i$ and $D / s^{2}$ determined from Equations (13) and (14), the MAE values are much higher for extreme temperatures, namely 40 and $70^{\circ} \mathrm{C}$, and they are the following: 0.0815 , $0.0377,0.0 .0425$, and 0.0856 (for the mentioned temperatures, respectively).

The results of the validation of Biot number estimation are the following. The validation was done using the experimental data of drying kinetics of parsley root (Berlińska variety, $6 \mathrm{~mm}$ thick slices) dried in natural convection conditions at $55^{\circ} \mathrm{C}$. Biot number values were the following: 0.7281 and 0.7326 (Equations (11) and (13), respectively), whereas $D / s^{2}$ equalled 0.0067 (Equations (12) and (14)). Regardless of whether Equations (11) and (12) or (13) and (14) were used, $R^{2}=0.9955$, RMSE $=$ 0.0376 , and $\mathrm{MAE}=0.0336$, so the validation can be treated as satisfactory.

\section{Conclusions}

The analysis of Biot numbers enables questions about the controlling mechanisms employed for heat or mass transfer during the considered process to be answered.

This paper used a multi-objective optimization method (based on GA and Pareto optimization) for determination of the Biot number. A MOO GA method with a consideration of the simultaneous maximization of $R^{2}$ and minimization of RMSE and MAE between experimental data and the drying model was successfully applied.

The optimum values of the Biot number and constants of function used to determine the Biot number, gained by the MOO GA, were found. Eight types of equations for determining the $B i$ were tested. The Biot number can be calculated from the following equations: $B i=0.8193 \exp \left(-6.4951 T^{-1}\right)$ (and moisture diffusion coefficient from $D / s^{2}=0.00704 \exp \left(-2.54 T^{-1}\right)$ ) or $B i=1 / 0.1746 \log (1193847 \mathrm{~T})$ $\left(D / s^{2}=0.0075 \exp \left(-6 T^{-1}\right)\right)$. The results of statistical analysis were as follows: RMSE $=0.0672, \mathrm{MAE}=$ 0.0535 , and $R^{2}=0.98$ for the first equation for $B i$ and $D / s^{2}$ and RMSE $=0.0757$, MAE $=0.0604$, and $R^{2}=0.98$ for the second one. The conducted validation gave good results: $\mathrm{RMSE}=0.0376, \mathrm{MAE}=$ 0.0336 , and $R^{2}=0.9955$.

Author Contributions: K.G.: Proposal of the research topic, experiments, modelling, and writing of manuscript; R.W.: Optimization and writing of manuscript; A.K.: Writing of manuscript and critical revision of manuscript.

Funding: This research received no external funding.

Conflicts of Interest: The authors declare no conflicts of interest. 


\section{Nomenclature}

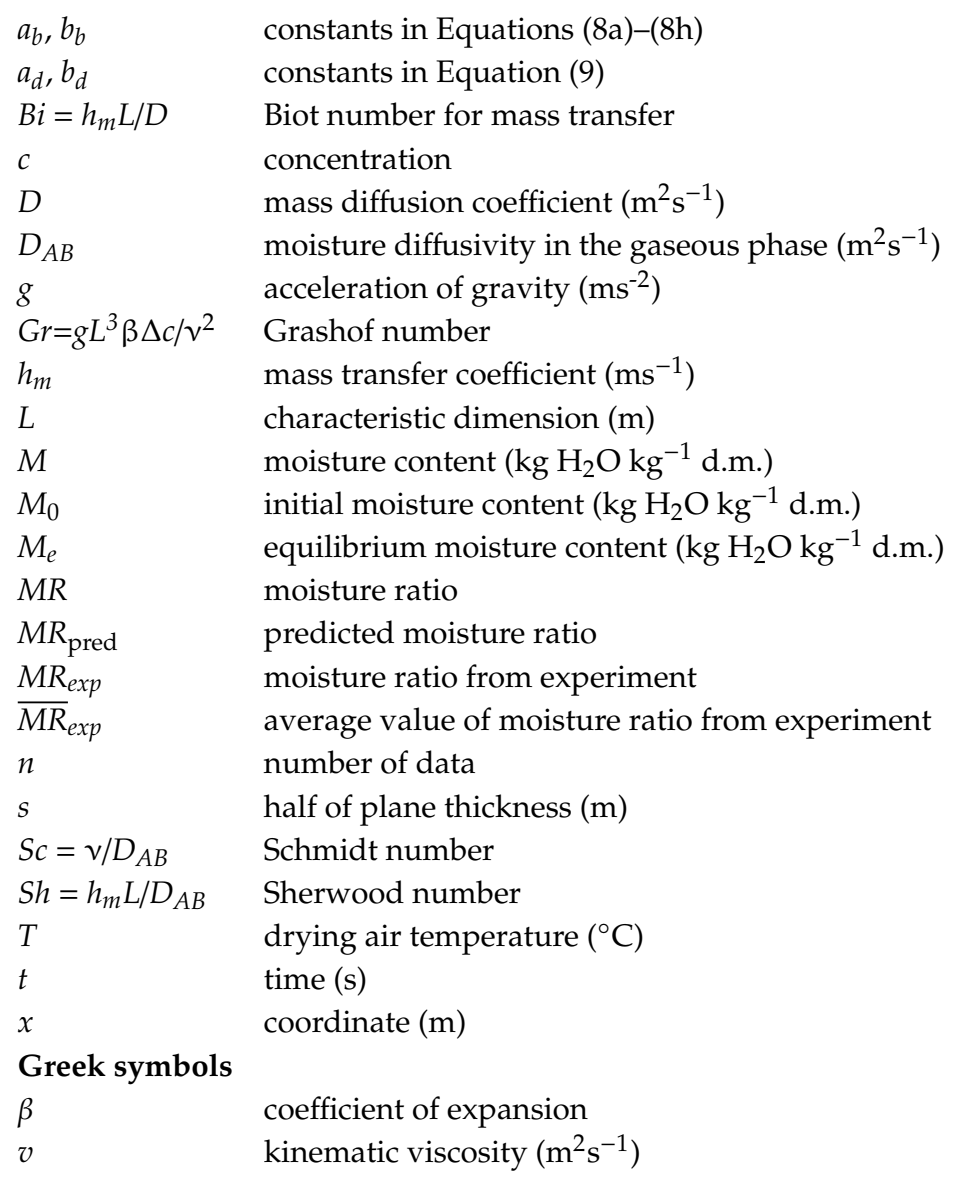

\section{References}

1. Giner, S.A.; Irigoyen, R.M.T.; Cicuttín, S.; Fiorentini, C. The variable nature of Biot numbers in food drying. J. Food Eng. 2010, 101, 214-222. [CrossRef]

2. Cuesta, F.J.; Lamúa, M.; Alique, R. A new exact numerical series for the determination of the Biot number: Application for the inverse estimation of the surface heat transfer coefficient in food processing. Int. J. Heat Mass Transf. 2012, 55, 4053-4062. [CrossRef]

3. Dincer, I. Moisture transfer analysis during drying of slab woods. Heat Mass Transf. 1998, 34, 317-320. [CrossRef]

4. Rovedo, C.O.; Suarez, C.; Viollaz, P. Analysis of moisture profiles, mass Biot number and driving forces during drying of potato slabs. J. Food Eng. 1998, 36, 211-231. [CrossRef]

5. Ruiz-López, I.I.; Ruiz-Espinosa, H.; Arellanes-Lozada, P.; Bárcenas-Pozos, M.E.; García-Alvarado, M.A. Analytical model for variable moisture diffusivity estimation and drying simulation of shrinkable food products. J. Food Eng. 2012, 108, 427-435. [CrossRef]

6. Ruiz-López, I.I.; Ruiz-Espinosa, H.; Luna-Guevara, M.L.; García-Alvarado, M.A. Modeling and simulation of heat and mass transfer during drying of solids with hemispherical shell geometry. Comput. Chem. Eng. 2011, 35, 191-199. [CrossRef]

7. Wu, Y.; Irudayaraj, J. Analysis of heat, mass and pressure transfer in starch based food systems. J. Food Eng. 1996, 29, 399-414. [CrossRef]

8. Górnicki, K.; Kaleta, A. Some problems related to mathematical modelling of mass transfer exemplified of convection drying of biological materials. In Heat and Mass Transfer; Hossain, M., Ed.; IntechOpen: Rijeka, Croatia, 2011.

9. Huang, C.-H.; Yeh, C.-Y. An inverse problem in simultaneous estimating the Biot numbers of heat and moisture transfer for a porous material. Int. J. Heat Mass Transf. 2002, 45, 4643-4653. [CrossRef] 
10. Dincer, I.; Hussain, M.M. Development of a new Biot number and lag factor correlation for drying applications. Int. J. Heat Mass Transf. 2004, 47, 653-658. [CrossRef]

11. Chen, X.D.; Peng, X. Modified Biot number in the context of air drying of small moist porous objects. Dry. Technol. 2005, 23, 83-103. [CrossRef]

12. Xie, Y.; Gao, Z.; Liu, Y.; Xiao, H. Pulsed vacuum drying of rhizoma dioscoreae slices. LWT 2017, 80, $237-249$. [CrossRef]

13. Dincer, I.; Dost, S. A modelling study for moisture diffusivities and moisture transfer coefficients in drying of solid objects. Int. J. Energy Res. 1996, 20, 531-539. [CrossRef]

14. Kiranoudis, C.T.; Markatos, N.C. Pareto design of conveyor-belt dryers. J. Food Eng. 2000, 46, 145-155. [CrossRef]

15. Kiranoudis, C.T.; Maroulis, Z.B.; Marinos-Kouris, D. Product quality multi-objective dryer design. Dry. Technol. 1999, 17, 2251-2270. [CrossRef]

16. Krokida, M.K.; Kiranoudis, C.T. Pareto design of fluidized bed dryers. Chem. Eng. J. 2000, 79, 1-12. [CrossRef]

17. Krokida, M.K.; Kiranoudis, C.T. Product quality multi-objective optimization of fluidized bed dryers. Dry. Technol. 2000, 18, 143-163. [CrossRef]

18. Quirijns, E.J. Modelling and Dynamic Optimisation of Quality Indicator Profiles during Drying. PhD Thesis, Wageningen University, Wageningen, The Netherland, April 2006.

19. Olmos, A.; Trelea, I.C.; Courtois, F.; Bonazzi, C.; Trystram, G. Dynamic optimal control of batch rice drying process. Dry. Technol. 2002, 20, 1319-1345. [CrossRef]

20. Winiczenko, R.; Górnicki, K.; Kaleta, A.; Martynenko, A.; Janaszek-Mańkowska, M.; Trajer, J. Multi-objective optimization of convective drying of apple cubes. Comput. Electron. Agric. 2018, 145, 341-348. [CrossRef]

21. Winiczenko Górnicki, K.; Kaleta, A.; Janaszek-Mankowska, M.; Trajer, J. Multi-objective optimization of the apple drying and rehydration processes parameters. Emir. J. Food Agric. EJFA 2018, 30, 1-9.

22. Chen, C.R.; Ramaswamy, H.S. Modeling and optimization of variable retort temperature (VRT) thermal processing using coupled neural networks and genetic algorithms. J. Food Eng. 2002, 53, 209-220. [CrossRef]

23. Erdoğdu, F.; Balaban, M.O. Complex method for nonlinear constrained multi-criteria (multi-objective function) optimization of thermal processing. J. Food Process Eng. 2003, 26, 357-375. [CrossRef]

24. Górnicki, K.; Kaleta, A. Modelling convection drying of blanched parsley root slices. Biosyst. Eng. 2007, 97, 51-59. [CrossRef]

25. Luikov, A.V. Analytical Heat Diffusion Theory; Academic Press Inc.: New York, NY, USA, 1970.

26. Zielinska, M.; Markowski, M. Drying behavior of carrots dried in a spout-fluidized bed dryer. Dry. Technol. 2007, 25, 261-270. [CrossRef]

27. Celma, A.R.; Cuadros, F.; López-Rodríguez, F. Convective drying characteristics of sludge from treatment plants in tomato processing industries. Food Bioprod. Process. 2012, 90, 224-234. [CrossRef]

28. Nguyen, T.H.; Lanoisellé, J.L.; Allaf, T.; Allaf, K. Experimental and fundamental critical analysis of diffusion model of airflow drying. Dry. Technol. 2016, 34, 1884-1899. [CrossRef]

29. Górnicki, K.; Kaleta, A. Drying curve modelling of blanched carrot cubes under natural convection condition. J. Food Eng. 2007, 82, 160-170. [CrossRef]

30. Chen, X.D.; Lin, S.X.Q.; Chen, G. On the ratio of heat to mass transfer coefficient for water evaporation and its impact upon drying modeling. Int. J. Heat Mass Transf. 2002, 45, 4369-4372. [CrossRef]

31. Bird, R.B.; Stewart, W.E.; Lightfoot, E.N. Transport Phenomena; Rev. 2nd ed.; Wiley: New York, NY, USA, 2007; ISBN 978-0-470-11539-8.

32. Zogzas, N.P.; Maroulis, Z.B.; Marinos-Kouris, D. Moisture diffusivity data compilation in foodstuffs. Dry. Technol. 1996, 14, 2225-2253. [CrossRef]

33. Mujumdar, A.S. Handbook of Industrial Drying, 4th ed.; CRC Press, Taylor \& Francis Group: Boca Raton, FL, USA, 2015; ISBN 978-1-4665-9665-8.

(C) 2019 by the authors. Licensee MDPI, Basel, Switzerland. This article is an open access article distributed under the terms and conditions of the Creative Commons Attribution (CC BY) license (http://creativecommons.org/licenses/by/4.0/). 